\title{
The bearing capacity of footings on sand with a weak layer
}

1 Calogero Valore

Full Professor, Dipartimento di Ingegneria Civile, Ambientale, Aerospaziale e dei Materiali, Università degli Studi di Palermo, Palermo, Italy

2. Maurizio Ziccarelli PhD

Assistant Professor, Dipartimento di Ingegneria Civile, Ambientale, Aerospaziale e dei Materiali, Università degli Studi di Palermo,

Palermo, Italy (corresponding author: maurizio.ziccarelli@unipa.it)
3 Sandro Rino Muscolino PhD

Research Fellow, Dipartimento di Ingegneria Civile, Ambientale, Aerospaziale e dei Materiali, Università degli Studi di Palermo, Palermo, Italy


Minor details of the ground, such as thin weak layers, shear bands and slickensided surfaces, can substantially affect the behaviour of soil-footing and other geotechnical systems, despite their seeming insignificance. In this paper, the influence of the presence of a thin horizontal weak layer on the ultimate bearing capacity of a strip footing on dense sand is investigated by single-gravity tests on small-scale physical models of the soil-footing system. The test results show that the weak layer strongly influences both the failure mechanism and the ultimate bearing capacity if its depth is lower than about four times the footing width. It is found that the presence of a thin weak layer can cause decreases of the ultimate bearing capacity of up to $\mathbf{8 0 \%}$. Numerical simulations, by finite-element analysis, of the behaviour of the reduced-scale models are able to capture the failure mechanism and the ultimate bearing capacity correctly, only if the mean equivalent constant value of the secant angle of shearing resistance used in calculations is selected, taking into account the curvature of the shear strength envelope of the sand within the very low normal stress range existing in the tested models.

\section{Notation}

$B \quad$ footing width

$C_{\mathrm{U}} \quad$ uniformity coefficient

$c_{1 \mathrm{p}}^{\prime} \quad$ cohesion intercept of sand

$D_{\mathrm{r}} \quad$ relative density

d particle diameter

$d_{10} \quad$ particle diameter corresponding to $10 \%$ of finer by weight

$d_{50}$ mean particle size

$d_{60}$ particle diameter corresponding to $60 \%$ of finer by weight

$d_{\max }$ maximum particle size of sand

$d_{\min } \quad$ minimum particle size of sand

$E^{\prime} \quad$ Young's modulus

e void ratio

$e_{0} \quad$ initial void ratio

$e_{\max }$ maximum void ratio

$e_{\min }$

$G_{\mathrm{s} 1}$

$K_{0}$

$L$

$l_{\mathrm{m}}$

$N_{\gamma}$

$n_{0}$

$n$

minimum void ratio

specific gravity of sand

coefficient of earth pressure at rest

footing length

lateral extent of failure mechanism

bearing capacity factor

initial porosity

porosity

$\eta$
$Q$

$q$

$q_{\text {lim }}$

$q_{\text {lim }, 0}$

$t_{0}$

$z_{i}$

$Z_{\mathrm{m}}$

$\gamma_{\mathrm{d} 1}$

$\gamma_{\mathrm{d} 2}$

$\gamma_{\mathrm{s} 1}$

$\delta^{\prime}$

$\delta_{1}^{\prime}$

$\theta$

vertical load applied to the footing mean vertical pressure acting on the footing base ultimate (or limit) bearing pressure (at peak) or ultimate bearing capacity

ultimate bearing pressure (at peak) of footing on homogeneous sand bed thickness of weak layer depth from the ground surface of weak layer depth from the ground surface of the deepest point of the failure mechanism unit weight of sand dry weight of sand dry unit weight of weak layer specific unit weight of sand angle of shearing resistance of the footing-sand interface angle of friction of the glass-sand interface ratio $q_{\text {lim }} / q_{\text {lim,o }}$ emersion angle of the failure surface: $\theta_{\mathrm{L}}$ and $\theta_{\mathrm{R}}$ on the left or right side of the footing, respectively

$v^{\prime} \quad$ Poisson's ratio

$\rho \quad$ settlement of the footing

$\rho_{\text {lim }} \quad$ settlement of the footing in correspondence of $q_{\text {lim }}$

$\sigma^{\prime} \quad$ normal effective stress 
$\sigma_{\mathrm{v}}^{\prime} \quad$ vertical effective stress

$\tau \quad$ shear stress

$\phi_{1}^{\prime} \quad$ angle of shearing resistance of sand

$\phi_{1 \mathrm{cv}}^{\prime} \quad$ angle of shearing resistance of sand at constant volume

$\phi_{1 \mathrm{p}}^{\prime} \quad$ peak angle of shearing resistance of sand

$\phi_{1 \mathrm{p}}^{\prime *} \quad$ mean equivalent constant value of secant angle of shearing resistance of sand

$\phi_{2 p}^{\prime} \quad$ angle of shearing resistance of the weak layer

$\psi_{1 \mathrm{p}}^{\prime} \quad$ peak dilation angle of sand

$\psi_{1 \mathrm{p}}^{\prime *} \quad$ dilation angle corresponding to $\phi_{1 \mathrm{p}}^{\prime *}$

\section{Introduction}

Minor structural features can exist in natural soil and rock masses as well as in earthworks. They include thin syngenetic seams and laminae such as those occurring in varved soils, thin shear bands and sliding surfaces brought about by past instability processes, interfaces between different materials, structural discontinuities, contact surfaces (sometimes slickensided) between successive lifts in earth embankments. These 'details' may differ considerably from the adjoining materials in terms of index properties, shear strength, stiffness and hydraulic conductivity. Due to their thinness, they may pass undetected even when an ordinarily suitable ground investigation programme has been carried out. Terzaghi (1929) termed these features 'minor geologic details' and pointed out their enormous potential effects on the safety of dams; many subsequent studies (e.g. Rowe (1972, 1991), Leonards (1982), Scott (1987), Skempton and Vaughan (1993)) considerably added to the subject. The influence of minor geologic details of the ground on which the footing is founded does not appear, to the authors' knowledge, to have been systematically investigated yet. The simplest of such details is exemplified by a thin horizontal soil layer weaker than the soil in which it is interposed. In the present paper, the results of an investigation into the influence of such a weak layer on the ultimate bearing capacity of strip footings on dense sand, by means of tests on reduced-scale physical models, are reported and discussed.

The problem is schematised in Figure 1. Plane strain conditions are considered. The strip footing is rigid and rests on the ground surface. The embedment depth is initially nil. The foundation soil consists of two materials: dry sand (variety A or B) and a thin

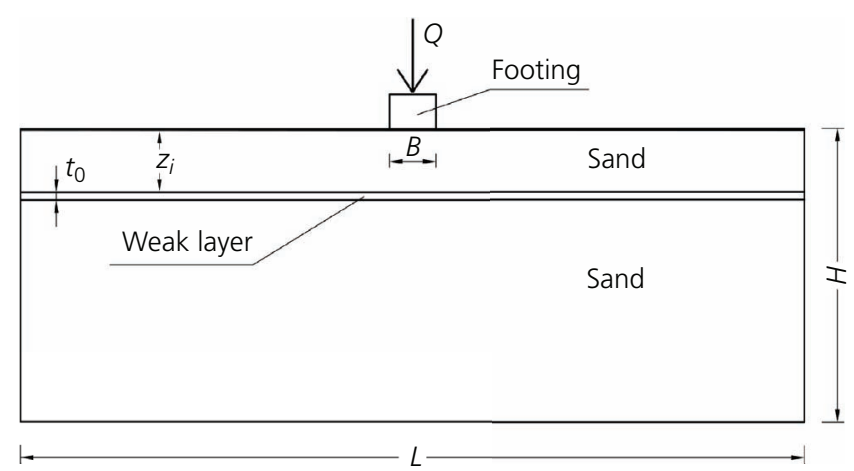

Figure 1. Scheme for the formulation of the problem layer, with thickness $t_{0}$, composed of a material weaker than the sand, located at depth $z_{i}$. The initial dry unit weight of the sand is $\gamma_{\mathrm{d} 1}$. The peak angles of the shearing resistance of the sand and of the weak material are respectively $\phi_{1 \mathrm{p}}^{\prime}$ and $\phi_{2 \mathrm{p}}^{\prime}$. Actually, the foundation soil consists of three layers (except when the weak layer is lacking) - namely, an upper and a lower sand layer plus the interposed weak layer. The load $Q$ is vertical and centred. The sand is initially homogeneous in terms of its index properties; however, its shear strength parameters and stiffness in the physical model may not be constant within the relevant geotechnical volume of the foundation soil because of the curvature of the failure envelope in the range of very low stresses.

The main aim of the tests on reduced-scale models is to get a first insight into the effects of the weaker layer on the failure mechanisms and on the ultimate bearing capacity.

\section{Experimental set-up and testing procedure}

The experimental set-up is shown schematically in Figure 2. It consists of a parallelepipedal stiff box having the following outer dimensions: length: $1123 \mathrm{~mm}$; width: $240 \mathrm{~mm}$; height: $520 \mathrm{~mm}$. The inside available space is $1000 \mathrm{~mm}$ long, $100 \mathrm{~mm}$ wide and $380 \mathrm{~mm}$ high. The front and rear walls of the box are made of poly(methyl methacrylate) (PMMA) plates, $25 \mathrm{~mm}$ thick, while the side walls are $20 \mathrm{~mm}$ thick. The bottom is also made of PMMA. The box rests on an $18 \mathrm{~mm}$ thick steel plate from which four vertical tee-steel sections stem at the corners; they are connected, in turn, to other horizontal steel sections in order completely to frame and stiffen the PMMA box. The lateral displacements of the front and rear walls can be considered negligible so that the plane strain (or two-dimensional (2D)) conditions apply. To reduce friction, the inside surfaces of the box are covered with a $2 \mathrm{~mm}$ thick glass sheet (see detail in Figure 2). The glass surface is coated with transparent silicone oil. The base of the box is tightly clamped onto the ram platen of a motorised hydraulic press. Other details of the apparatus are reported by Muscolino (2001).

The model footing is rigid; its width $B$ is 40 or $60 \mathrm{~mm}$, while its length $L$ is $100 \mathrm{~mm}$ in both cases. At the top, the footing is connected to a vertical piston guided by an axial ball bushing so that the footing can move only vertically; the piston is connected, in turn, to a proving ring (or to a load cell) that reacts against the cross-head of the press. The footing is loaded by driving the box upwards by means of the press ram at a constant displacement rate of $0.6 \mathrm{~mm} / \mathrm{min}$.

The settlements of the footing are measured by a dial gauge. To reveal visually the displacements at different depths and the failure mechanism, initially horizontal rows of coloured sand particles are carefully placed in the sand layers and in contact with the glass sheet. To set a visual reference for displacements and distortions of the sand and the weak layer, a square grid of vertical and horizontal lines was carved on the external surface of the front PMMA wall. A digital camera was used to take pictures of the front wall in order to exploit the particle image velocimetry 

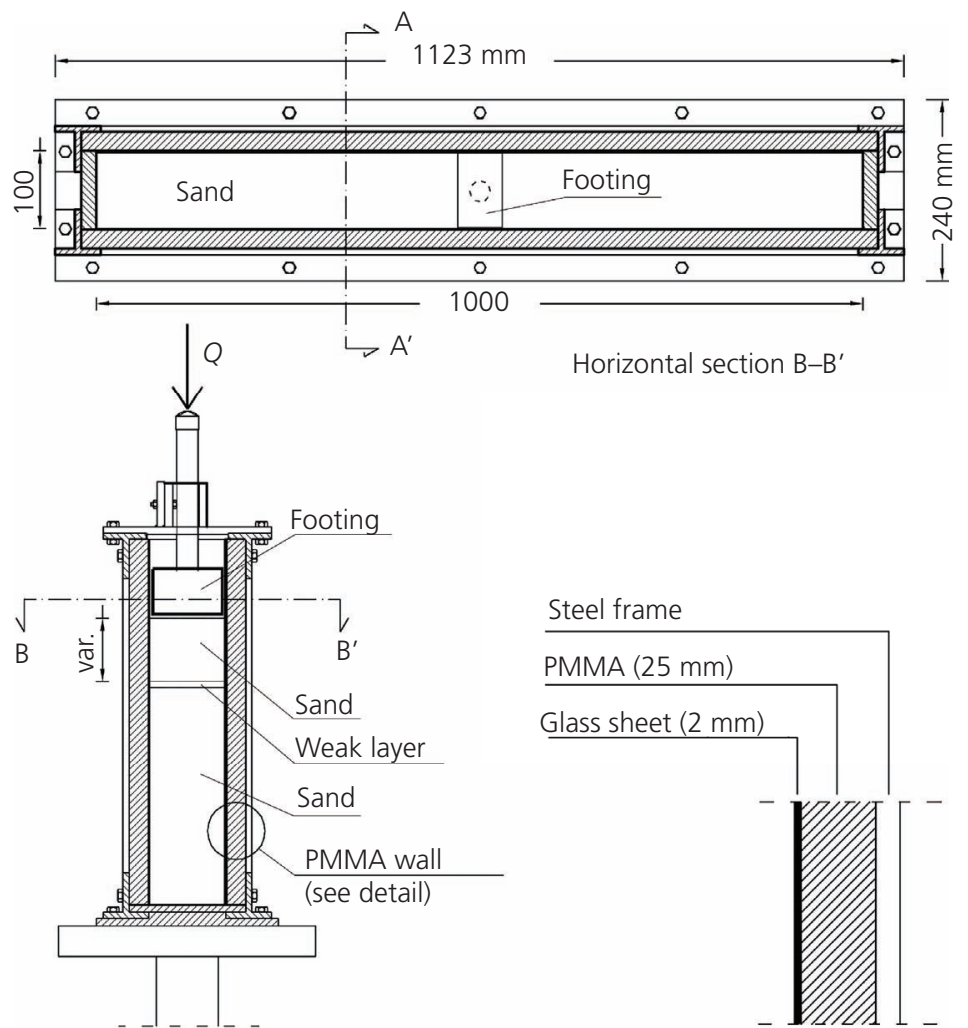

Steel frame

PMMA (25 mm)

Glass sheet (2 mm)

Vertical section $\mathrm{A}-\mathrm{A}^{\prime}$

$$
A^{\prime}
$$
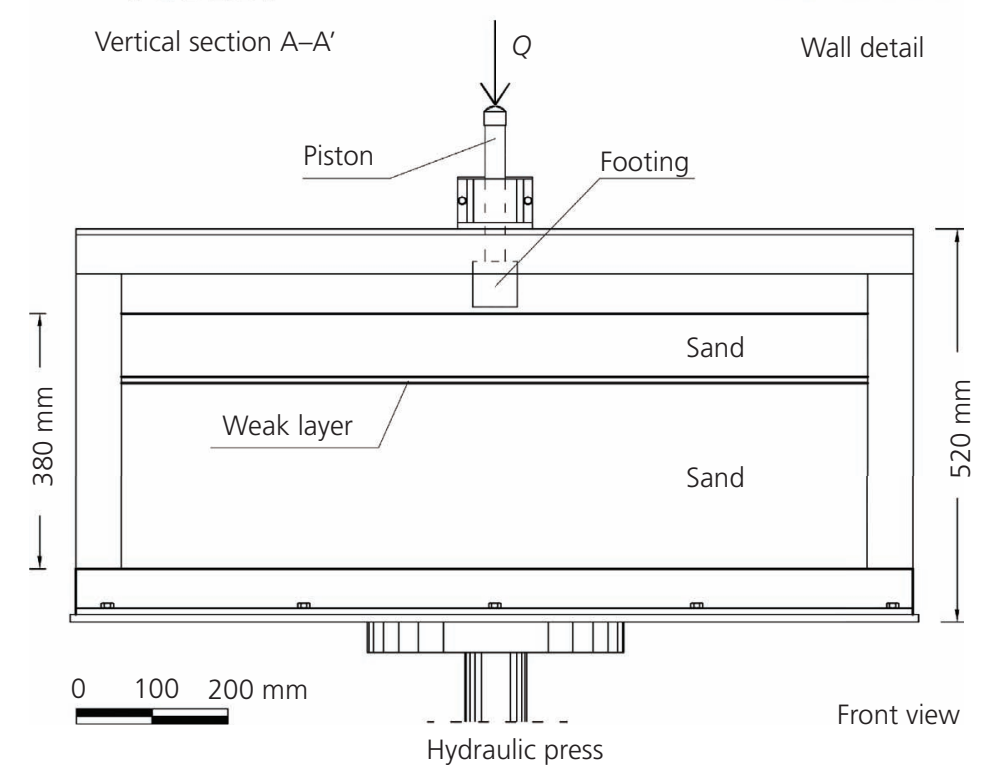

Figure 2. Experimental set-up

(PIV) technique for catching the evolution of soil displacements and the formation of the failure mechanism.

\section{Materials}

\section{Sands}

The soil layer consists of silica sand. Two sands, A and B, have been used. The sand grains are from subrounded to angular. The sands are essentially composed of silica (more than 95\%) and traces of feldspars and calcite. The sand has been deposited by dry pluviation at a constant height of fall to achieve uniformity of the index properties within the sand. The target density was obtained by calibrating the height of fall and the size of the spreader hole. The height of fall of $1 \mathrm{~m}$ was kept constant during the deposition. Initial index properties of the sands are summarised in Table 1. 
Table 1. Initial index properties of the silica sands A and B

\begin{tabular}{|c|c|c|c|c|c|c|c|c|c|c|c|c|c|c|}
\hline Sand & $G_{s 1}$ & $\begin{array}{c}\gamma_{s 1}: \\
k N / m^{3}\end{array}$ & $n_{0}$ & $e_{0}$ & $e_{\min }$ & $e_{\max }$ & $D_{\mathrm{r}}: \%$ & $\begin{array}{c}\gamma_{\mathrm{d} 11}: \\
\mathrm{kN} / \mathrm{m}^{3}\end{array}$ & $\begin{array}{l}d_{\max }: \\
\mathrm{mm}\end{array}$ & $\begin{array}{l}d_{60}: \\
\mathrm{mm}\end{array}$ & $\begin{array}{l}d_{50}: \\
\mathrm{mm}\end{array}$ & $\begin{array}{l}d_{10}: \\
\mathrm{mm}\end{array}$ & $\begin{array}{l}d_{\min }: \\
\mathrm{mm}\end{array}$ & $\begin{array}{c}C_{U}=d_{60} / \\
d_{10}\end{array}$ \\
\hline A & 2.65 & 26 & 0.383 & 0.622 & 0.606 & 0.798 & 92 & 16 & $2 \cdot 36$ & 0.97 & 0.95 & 0.72 & 0.30 & $1 \cdot 35$ \\
\hline B & 2.65 & 26 & 0.393 & 0.647 & 0.634 & 0.897 & 95 & $15 \cdot 8$ & 0.85 & 0.47 & 0.45 & 0.33 & 0.18 & $1 \cdot 42$ \\
\hline
\end{tabular}

Minimum and maximum void ratios ( $e_{\min }$ and $e_{\max }$ ) were determined according to ASTM standards D 4253-00 and D 4254-00 (ASTM, 2004a, 2004b)

The relative density, $D_{\mathrm{r}}$, was determined according to ASTM standards D 4253-00 and D 4254-00 (ASTM, 2004a, 2004b). Since the ratio $B / d_{50}$ is greater than 50 - specifically, $63 \cdot 2$ for $B=$ $60 \mathrm{~mm}$ and 88.9 for $B=40 \mathrm{~mm}$ for footing on sands A and B, respectively - the particle size effect can be considered negligible according to recommendations made by many researchers (e.g. Bolton and Lau (1989), Taylor (1995), Toyosawa et al. (2013)).

The crushing of sand particles is negligible considering its mineralogical composition and the low stress level existing in the tested physical models (Valore and Ziccarelli, 2009).

The shear strength parameters of sands were determined by nine triaxial and 27 direct shear tests for sand $\mathrm{A}$ and by 12 direct shear tests for sand $\mathrm{B}$. The triaxial compression tests were performed on dry sand (four consolidated drained (CD) tests) and on back pressuresaturated sand (one $\mathrm{CD}$ test and four isotropically consolidated undrained tests); the direct shear tests were carried out on dry sand. Results of tests concerning sand A are shown in Figure 3.

The peak strength failure envelope of both sands is definitely curvilinear. The shear strength parameters of sand A vary in function of the normal stress level as shown in Figure 3. The angle $\phi_{1 \mathrm{p}}^{\prime}$ obtained from triaxial tests on saturated specimens is slightly lower than that from dry ones. The results of direct shear tests on dry sand confirm the curvature of the failure envelope. For very low effective stresses, $\sigma_{\mathrm{v}}^{\prime}(<10 \mathrm{kPa}), \phi_{1 \mathrm{p}}^{\prime}$ is higher than $50^{\circ}$, and for $\sigma_{\mathrm{v}}^{\prime}$ of the order of $1-2 \mathrm{kPa}$, it may exceed $60^{\circ}$. The angle of shear strength at constant volume (or at critical porosity), $\phi_{1 \mathrm{cv}}^{\prime}$, obtained by means of triaxial tests and direct shear tests, is $34^{\circ}$. The shear strength parameters of sand B vary as follows: $c_{1 \mathrm{p}}^{\prime}=0$ and $\phi_{1 \mathrm{p}}^{\prime}>50^{\circ}$ for $\sigma_{\mathrm{v}}^{\prime}<20 \mathrm{kPa} ; c_{1 \mathrm{p}}^{\prime}=0$ and $\phi_{1 \mathrm{p}}^{\prime}=50^{\circ}$ for $20<\sigma_{\mathrm{v}}^{\prime}<50 \mathrm{kPa} ; c_{1 \mathrm{p}}^{\prime}=$ 0 and $\phi_{1 \mathrm{p}}^{\prime}=45^{\circ}$ for $\sigma^{\prime}>50 \mathrm{kPa} ; \phi_{1 \mathrm{cv}}^{\prime}=32^{\circ}$.

These results are in good agreement with data reported in the literature (Celauro et al., 2014; Chakraborty and Salgado, 2010; Lancelot et al., 2006; Loukidis and Salgado, 2011; Negussey and Vaid, 1990; Ponce and Bell, 1971; Rowe, 1962; Sture et al., 1998; Yamaguchi et al., 1977).

The curvature of the failure envelope in the very low effective stress range is the most important single cause of the scale effects that afflict $1 \boldsymbol{g}$ tests on reduced-scale models; it cannot be neglected in the interpretation of the results of single-gravity physical tests (Hettler and Gudheus, 1988; Kumar and Khatri, 2008; Lau and Bolton, 2011a).

The angle of shearing strength for plane strain conditions is higher than the one obtained by triaxial tests due to the influence of the intermediate effective principal stress (Roscoe, 1970; Rowe, 1969; Sayão and Vaid, 1996). When $D_{\mathrm{r}}$ is greater than $90 \%$ (relevant to the present research), the plane strain value of $\phi_{1 \mathrm{p}}^{\prime}$ may exceed the triaxial one by as much as $7^{\circ}$ for values of the angle of shearing resistance at constant volume $\phi_{1 \mathrm{cv}}^{\prime}$ ranging from $30^{\circ}$ to $40^{\circ}$ (Abelev and Lade, 2004; Green and Bishop, 1969; Hoque and Tatsuoka, 1998; Lade and Duncan, 1973; Oda, 1981).

\section{Materials making up the weak layer}

Four materials have been used: three varieties of white dry talc powder $\left[\mathrm{Mg}_{3} \mathrm{Si}_{4} \mathrm{O}_{10}(\mathrm{OH})_{2}\right]$, namely, Baker, Luzenac 2 and $\mathrm{CM} 3$,

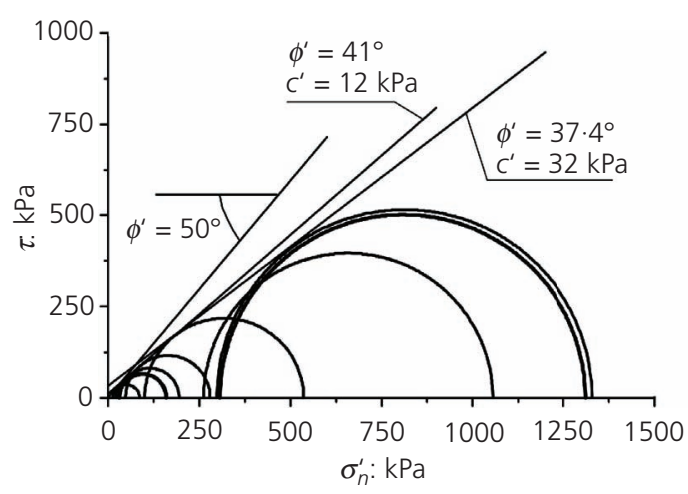

(a)

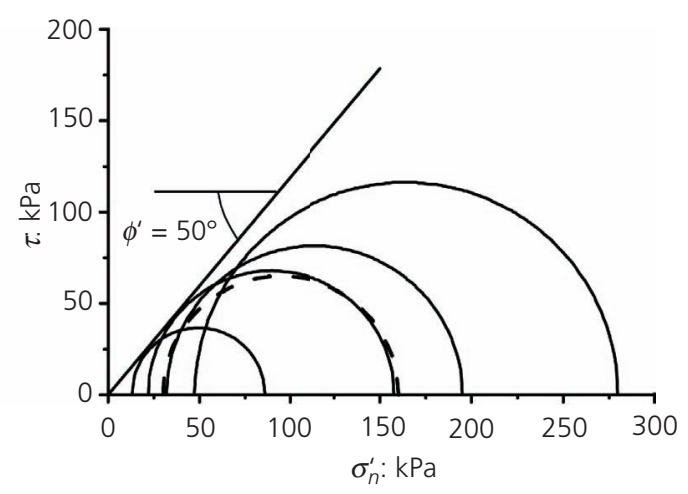

(b)

Figure 3. Results of triaxial tests on sand A: (a) all tests; (b) tests at low stresses (dashed circle is relative to saturated sand) 
Table 2. Angle of peak shear strength $\phi_{2 p}^{\prime}$ of the weak layer

\begin{tabular}{|lc|} 
Material & $\phi_{2 \mathrm{p}}^{\prime}:^{\circ}$ \\
\hline Dry Baker talc powder & 31 \\
Dry Luzenac 2 talc powder & 18 \\
Dry CM3 talc powder & 27 \\
Humidified bentonite & 11
\end{tabular}

and bentonite (sodium ( $\mathrm{Na}$ ) montmorillonite) placed dry and then humidified by spraying distilled water. The peak angles of shear strength of these materials were determined by direct shear tests and are summarised in Table 2. The cohesion intercept and the dilation angle of the mentioned materials are negligible. The angle of shearing resistance of the bentonite (sodium montmorillonite) was determined by direct shear tests on specimens made of a bentonite layer that is $4 \mathrm{~mm}$ thick interposed between two sand layers; this 'sandwich' intended to reproduce the sand-bentonite system of the physical model at the relevant stresses. The water content of the bentonite was $75-85 \%$. The obtained value of the angle of shear strength, $\phi_{2 p}^{\prime}$, of the bentonite is in good agreement with the published data (e.g. Mesri and Olson (1970), Mesri and Olson (1971), Domitrovic and Kovacevic Zelic (2013)). It is worth mentioning in passing that calcium $(\mathrm{Ca})$ montmorillonite can show higher values of $\phi_{2 p}^{\prime}$ (Hattab et al., 2015).

The weak layer thickness is typically between 3 and $4 \mathrm{~mm}$; see Table 3.

\section{Footing}

The width $B$ of the footing is 40 or $60 \mathrm{~mm}$, while its length $L$ is $100 \mathrm{~mm}$. The footing is made of aluminium and can be considered rigid; its settlements are uniform. The front and rear sides of the footing were coated with polytetrafluoroethylene to minimise friction at the interface with the front and rear glass sheets of the testing box. Sandpaper was glued onto the footing base. The peak angle of shearing resistance, $\delta^{\prime}$, of the interface between silica sand and sandpaper was $42^{\circ}$ as determined by direct shear tests, so the sand-footing contact can be considered perfectly rough according to Hansen and Christensen (1969) and Kumar and Kouzer (2007), since $\delta^{\prime} / \phi_{1 \mathrm{p}}^{\prime}>0.7$ for $\phi_{1 \mathrm{p}}^{\prime}=50^{\circ}$.

\section{Glass-sand friction}

The glass sheets have been lubricated with silicone oil. However, the interface is not perfectly smooth. The angle of friction $\delta_{1}^{\prime}$ of the sand-glass interface depends on the viscosity of the lubricating oil, the stress level, strain rate and smoothness of the glass surface (Goto et al., 1993; Tatsuoka et al., 1984). Tatsuoka and Haibara (1985) reported values of $\delta_{1}^{\prime}$ to be between $5^{\circ}$ and $7^{\circ}$ relative to the interface between Toyoura sand (which is a fine, essentially silica, sand) and non-lubricated acetone-cleaned glass.

Although in the experiments at hand the glass-sand friction is not nil, it is believed that the actual deformation state can be considered approximately 2D.

Table 3. Sand A: results of $\mathbf{1} \boldsymbol{g}$ tests performed on physical models of strip footings resting on sand bed containing a thin horizontal weak layer

\begin{tabular}{|c|c|c|c|c|c|c|c|c|c|c|c|c|}
\hline Weak layer & Test & $z_{i} / B$ & $t_{0}: \mathrm{mm}$ & $I_{\mathrm{m}} / B$ & $z_{m}: m m$ & $z_{m} / B$ & $\theta_{\mathrm{L}}:^{\circ}$ & $\theta_{\mathrm{R}}:^{\circ}$ & $q_{\mathrm{lim}}: \mathrm{kPa}$ & $q_{\lim } / q_{\lim , 0}$ & $\rho_{\text {lim }}: \mathrm{mm}$ & $\rho_{\mathrm{lim}} / B$ \\
\hline \multirow[t]{8}{*}{ Dry Baker talc } & B05 & $1 \cdot 47$ & 2 & $2 \cdot 50$ & $88 \cdot 2$ & 1.47 & 40 & 36 & $307 \cdot 9$ & 0.82 & $8 \cdot 7$ & 0.14 \\
\hline & B07 & 0.50 & $2 \cdot 5$ & $4 \cdot 75$ & 105 & 1.75 & 32 & - & $371 \cdot 3$ & 0.99 & $9 \cdot 1$ & 0.15 \\
\hline & B08 & 0.95 & 3 & $2 \cdot 50$ & 57 & 0.95 & - & 33 & 333.0 & 0.89 & $8 \cdot 8$ & 0.15 \\
\hline & B09 & $1 \cdot 20$ & $2 \cdot 5$ & $3 \cdot 00$ & 72 & $1 \cdot 20$ & 34 & 41 & $318 \cdot 8$ & 0.85 & $9 \cdot 0$ & 0.15 \\
\hline & B10 & 2.92 & 3 & $3 \cdot 50$ & 90 & $1 \cdot 50$ & 45 & - & $308 \cdot 4$ & 0.82 & $9 \cdot 2$ & 0.15 \\
\hline & B11 & 1.95 & $2 \cdot 5$ & $5 \cdot 25$ & 117 & 1.95 & 42 & 35 & $306 \cdot 8$ & 0.82 & $8 \cdot 7$ & 0.15 \\
\hline & B19 & $2 \cdot 50$ & 3 & $2 \cdot 25$ & 60 & 1.00 & 41 & - & $303 \cdot 5$ & 0.81 & $8 \cdot 4$ & 0.14 \\
\hline & B20 & 2.67 & 3 & 6.75 & $160 \cdot 2$ & $2 \cdot 67$ & 36 & - & 291.5 & 0.78 & 8.7 & 0.15 \\
\hline \multirow[t]{9}{*}{ Dry Luzenac 2 talc } & B12 & $1 \cdot 87$ & 7 & $4 \cdot 20$ & $112 \cdot 2$ & 1.87 & 41 & 38 & $207 \cdot 2$ & 0.55 & $7 \cdot 1$ & 0.12 \\
\hline & B13 & 1.95 & 3 & $4 \cdot 50$ & 117 & 1.95 & - & 40 & $235 \cdot 7$ & 0.63 & $7 \cdot 8$ & 0.13 \\
\hline & B14 & $1 \cdot 20$ & 3 & 3.00 & 72 & $1 \cdot 20$ & 40 & 37 & $267 \cdot 4$ & 0.71 & $9 \cdot 2$ & 0.15 \\
\hline & B15 & $2 \cdot 92$ & 4 & 4.00 & 96 & 1.60 & - & 44 & $296 \cdot 9$ & 0.79 & $10 \cdot 1$ & 0.17 \\
\hline & B21 & $1 \cdot 10$ & 4 & $2 \cdot 80$ & 66 & $1 \cdot 10$ & 42 & 37 & $230 \cdot 2$ & 0.61 & $8 \cdot 1$ & 0.13 \\
\hline & B22 & 0.50 & 3 & $3 \cdot 60$ & 96 & 1.60 & 36 & 44 & 294.7 & 0.79 & $9 \cdot 3$ & 0.15 \\
\hline & B33 & 0.95 & 3 & $2 \cdot 90$ & 117 & 1.95 & - & - & $267 \cdot 4$ & 0.71 & $8 \cdot 5$ & 0.14 \\
\hline & B42 & 3.90 & 3 & $3 \cdot 40$ & $82 \cdot 8$ & $1 \cdot 38$ & - & - & $293 \cdot 7$ & 0.78 & $10 \cdot 0$ & 0.17 \\
\hline & B49 & $2 \cdot 43$ & 3 & $6 \cdot 80$ & $145 \cdot 8$ & 2.43 & - & - & $228 \cdot 0$ & 0.61 & 8.9 & 0.15 \\
\hline \multirow[t]{5}{*}{ Humidified bentonite } & B16 & $1 \cdot 20$ & 3 & $3 \cdot 00$ & 72 & $1 \cdot 20$ & 33 & 37 & $117 \cdot 6$ & 0.31 & $4 \cdot 2$ & 0.07 \\
\hline & B17 & 1.92 & 4 & $3 \cdot 50$ & $115 \cdot 2$ & 1.92 & 42 & - & $204 \cdot 0$ & 0.54 & $7 \cdot 1$ & 0.12 \\
\hline & B18 & 1.00 & 4 & $2 \cdot 25$ & 60 & 1.00 & - & 43 & $112 \cdot 6$ & 0.30 & $3 \cdot 8$ & 0.06 \\
\hline & B23 & 0.50 & 3 & 1.00 & 30 & $0 \cdot 50$ & - & - & $80 \cdot 4$ & 0.21 & $1 \cdot 7$ & 0.03 \\
\hline & B37 & $2 \cdot 97$ & 3 & $6 \cdot 60$ & $178 \cdot 2$ & $2 \cdot 97$ & - & - & $245 \cdot 5$ & 0.66 & $7 \cdot 0$ & 0.12 \\
\hline Homogeneous sand bed & B06 & - & - & $3 \cdot 25$ & 84 & $1 \cdot 4$ & - & 41 & $375 \cdot 1$ & 1 & $8 \cdot 29$ & $0 \cdot 14$ \\
\hline
\end{tabular}

Results of test B06 on homogeneous sand bed reported for comparison

$B=60 \mathrm{~mm}$, footing width; $z_{i}$, depth of the top surface of the weak layer; $t_{0}$, thickness of the weak layer; $q_{\text {lim, }}$ ultimate bearing capacity; $q_{\text {lim, } 0 \text {, }}$ ultimate bearing capacity for the homogeneous sand bed; $\rho_{\text {lim }}$, settlement of footing at limit pressure; $I_{m}$, maximum lateral extent of failure mechanism; $z_{m}$, maximum depth of failure mechanism; $q_{\text {lim, },}=375.1 \mathrm{kPa} ; \theta_{\mathrm{L}}$ and $\theta_{R}$, emersion angles of the failure surface on the left or right side of the footing, respectively; other symbols defined in Notation 


\section{Results of $1 \mathrm{~g}$ tests on physical models}

Fifty-four tests were performed in all (Muscolino, 2001), of which 45 were on sand A and 9 on sand B. Results of 18 of the tests performed on sand A are summarised in Table 3. Some tests were repeated at the same $z_{i} / B$ and are not listed in Table 3. Results of tests performed on sand B are summarised in Table 4. In Tables 3 and 4 , the following data are given: the ultimate bearing capacity $q_{\lim }$ and the footing settlement $\rho_{\text {lim }}$ corresponding to $q_{\text {lim }}$, the depth and the material making up the weak layer, the main geometric characteristics of the failure mechanism.

The homogeneous dry sand bed test and the tests on dry sand containing a weak layer made of dry talc powder were, of course, drained. The tests involving a weak layer made of humidified bentonite can also be considered drained on account of the rather low displacement rate imposed on the footing, of the small thickness of the bentonite layer and of the dryness and high draining capacity of the sand bounding it.

\section{Failure mechanisms}

Typical failure mechanisms are shown in Figures 4-7 for $B=$ $60 \mathrm{~mm}$ footing on sand $A$ and in Figure 8 for $B=40 \mathrm{~mm}$ footing on sand B. The displacement fields and failure mechanisms relative to tests carried out on footing resting on sand A obtained by PIV analysis (Liu and Iskander, 2010; McMahon and Bolton, 2011; White et al., 2003) are reported in Figures 9-11. General shear failure (Vesić, 1973) occurred in all the experiments. The development of the failure surface started from the edges of the footing and then propagated downwards and laterally outwards, accompanied by the heaving of the ground surface on both sides of the footing. The complete formation of the failure mechanism during the loading process was clearly observed visually only after the peak load and was revealed by a shear band of dilated sand and by distortions undergone by the coloured sand rows (see Figures 4 and 5). This was observed through the front and rear walls of the testing box. The thickness of the observed shear band ranges from $6 \cdot 1$ to $9 \cdot 1 \mathrm{~mm}$ corresponding to $(6 \cdot 3-9 \cdot 4) d_{50}$ for footings on sand A and from 3.2 to $5.4 \mathrm{~mm}$ corresponding to
$(7 \cdot 1-12) d_{50}$ for footings on sand B. In both cases, it is well within the range of (6-25) $d_{50}$ reported in geotechnical literature (Alshibli and Hasan, 2008; Finno et al., 1997; Mühlhaus and Vardoulakis, 1987; Tatsuoka, 2001; Tatsuoka et al., 1991).

In the case of the homogeneous sand bed, the failure surfaces resemble that of Prandtl (1920), but their lateral extent is smaller (see Figures 4 and 8(a)); moreover, the angle of emersion at the ground surface $\theta$ is close to $45^{\circ}-\psi_{1 \mathrm{p}}^{\prime} / 2$ instead of $45^{\circ}-\phi_{1 \mathrm{p}}^{\prime} / 2$, as found by Arens (1975).

The angles $\theta_{\mathrm{L}}$ or $\theta_{\mathrm{R}}$, reported in Tables 3 and 4 , differ from $45^{\circ}-\phi_{1 \mathrm{p}}^{\prime} / 2$ due to the dilation of the sand and range from 32 to $45^{\circ}$ for footings on sand $\mathrm{A}$ and from 33 to $38^{\circ}$ for footings on sand $\mathrm{B}$; they approximately correspond to $45^{\circ} \psi_{1 \mathrm{p}}^{\prime} / 2$.

If the depth of the weak layer does not exceed a critical value (about $4 B$ ), it strongly influences both the failure mechanism and the ultimate bearing capacity, $q_{\mathrm{lim}}$. The failure mechanism can cut across the weak layer when it is made of talc and is located at a



Figure 4. Homogeneous sand A bed. Failure mechanism observed in test B06. Thin lines are monogranular rows of blue-coloured sand particles adjacent to the box wall; they were initially horizontally aligned

Table 4. Sand B: results of $1 \boldsymbol{g}$ tests performed on physical models of strip footings resting on sand bed containing a thin horizontal weak layer

\begin{tabular}{|c|c|c|c|c|c|c|c|c|c|c|c|c|}
\hline Weak layer & Test & $z_{i} / B$ & $t_{0}: \mathrm{mm}$ & $I_{\mathrm{m}} / B$ & $z_{\mathrm{m}}: \mathrm{mm}$ & $z_{\mathrm{m}} / B$ & $\theta_{L}:{ }^{\circ}$ & $\theta_{\mathrm{R}}:^{\circ}$ & $q_{\text {lim }}: \mathbf{k P a}$ & $q_{\lim } / q_{\lim , 0}$ & $\rho_{\text {lim }}: m m$ & $\rho_{\text {lim }} / B$ \\
\hline \multirow[t]{6}{*}{ Dry CM3 talc powder } & $\mathrm{B} 62$ & 1.5 & 5 & $4 \cdot 30$ & 60 & 1.50 & 34 & 34 & 114 & 0.54 & 4.97 & 0.08 \\
\hline & B63 & 2.0 & 5 & $6 \cdot 45$ & 80 & 2.00 & 36 & 34 & 118 & 0.56 & $4 \cdot 86$ & 0.08 \\
\hline & B65 & 1.0 & 5 & 2.73 & 40 & 1.00 & 33 & 33 & 125 & 0.59 & $6 \cdot 33$ & 0.11 \\
\hline & B64 & 3.0 & 5 & 4.47 & 94 & $2 \cdot 35$ & 34 & - & 142 & 0.67 & $5 \cdot 36$ & 0.13 \\
\hline & B66 & 4.0 & 5 & $6 \cdot 68$ & 134 & 3.35 & - & 37 & 190 & 0.90 & $6 \cdot 44$ & 0.11 \\
\hline & B67 & 0.5 & 5 & $6 \cdot 40$ & 143 & 3.58 & - & 38 & 146 & 0.69 & $6 \cdot 23$ & 0.10 \\
\hline \multirow[t]{3}{*}{ Homogeneous sand bed } & B59 & - & - & $4 \cdot 85$ & 107 & $2 \cdot 67$ & - & 33 & 211 & - & $4 \cdot 35$ & 0.07 \\
\hline & B60 & - & - & $6 \cdot 10$ & 135 & $3 \cdot 38$ & - & 34 & 212 & - & 5.08 & 0.08 \\
\hline & B61 & - & - & $4 \cdot 10$ & 110 & 2.75 & - & 36 & 196 & - & $4 \cdot 21$ & 0.07 \\
\hline
\end{tabular}

Results of tests B59, B60 and B61 on homogeneous sand bed reported for comparison

$B=40 \mathrm{~mm}$, width of footing; $z_{i}$, depth of the top surface of the weak layer; $t_{0}=5 \mathrm{~mm}$, thickness of the weak layer; $q_{\text {limm, }}$ ultimate bearing capacity; $q_{\text {lim, }, 0}$, ultimate bearing capacity for the homogeneous sand case; $\rho_{\text {lim }}$, settlement of footing in correspondence of ultimate bearing capacity; $I_{\mathrm{m}}$, maximum lateral extent of failure mechanism; $z_{m}$ maximum depth of failure mechanism; $q_{\text {lim, }}=212 \mathrm{kPa} ; \theta_{\llcorner}$and $\theta_{R_{1}}$, emersion angles of the failure surface on the left or right side of the footing, respectively; other symbols defined in Notation 
Geotechnical Research

Volume 4 Issue GR1
The bearing capacity of footings on sand

with a weak layer

Valore, Ziccarelli and Muscolino small depth underneath the footing; see Figures 5(a) and 6(a). The failure mechanism usually develops in part along the weak layer (see Figures 5(b), 6(b), 6(c) and 7).

The ratio $\rho_{\mathrm{lim}} / B$ is almost constant for the weak layer made of talc powder and ranges from $0 \cdot 14$ to $0 \cdot 15$ for the Baker talc, from $0 \cdot 12$ to 0.17 for the Luzenac 2 talc and from 0.08 to 0.13 for the CM3 talc. For the weak layer made of humidified bentonite, the $\rho_{\text {lim }} / B$ ranges between $0 \cdot 03$ and $0 \cdot 12$.

The relationship between the normalised lateral extent of the failure mechanisms $\left(l_{\mathrm{m}} / B\right)$ and the depth of the weak layer $\left(z_{i} / B\right)$ is shown in Figure 12 for footings on sand A. The weak layer

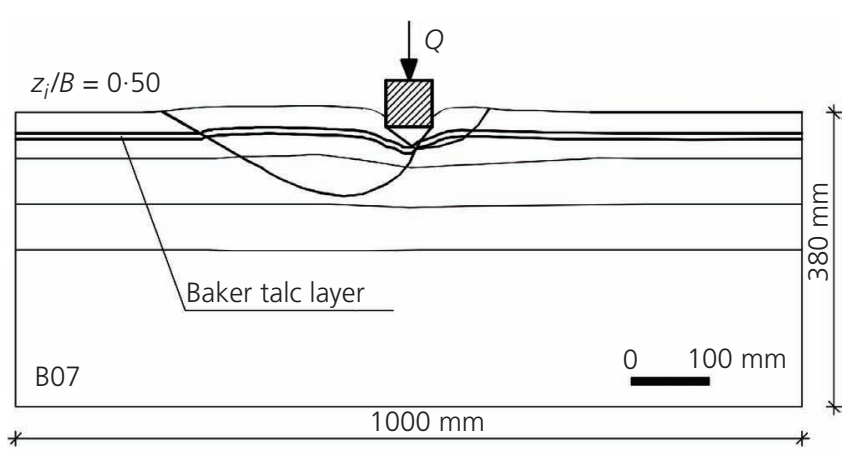

(a)



(b)

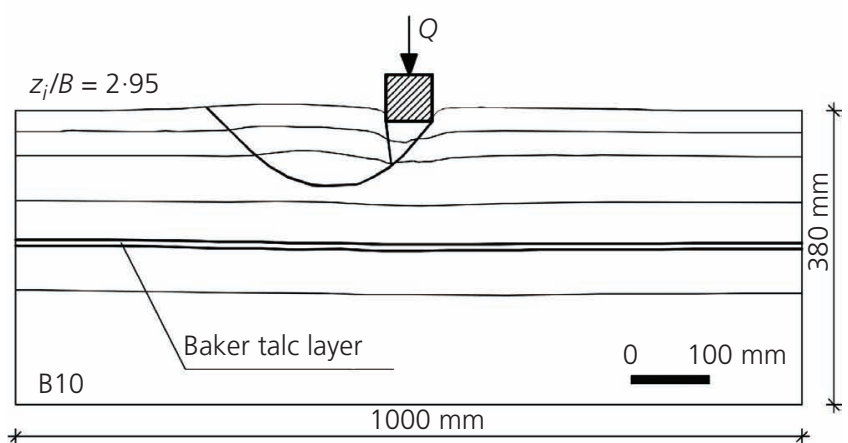

(c)

Figure 5. Sand A. Effect of the depth $z_{i}$ of the weak layer on the failure mechanisms observed in tests (a) B07, (b) B08 and (c) B10. Weak layer made of dry Baker talc powder; shown by double bold lines. Other lines: monogranular coloured sand particles

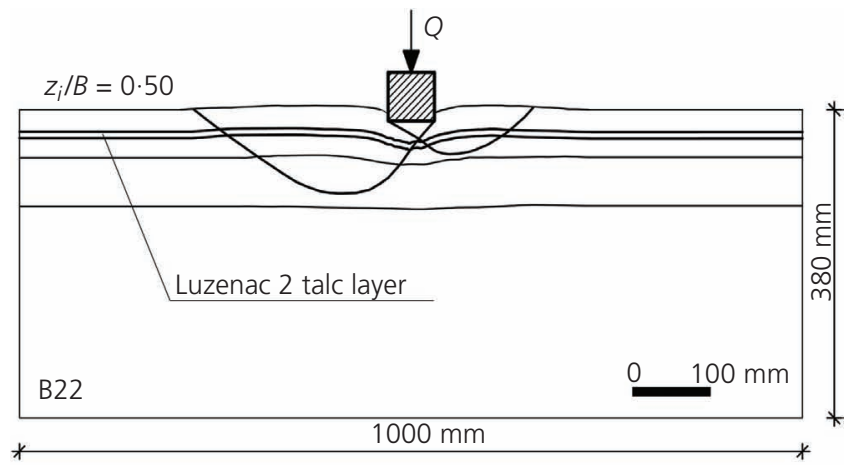

(a)

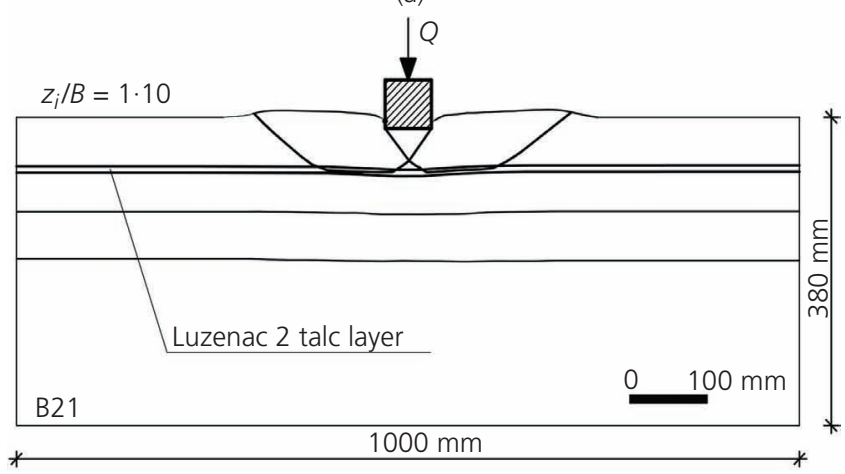

(b)

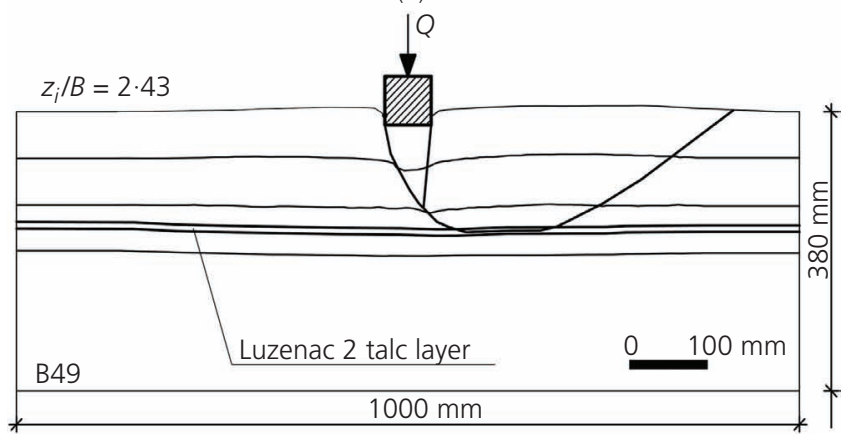

(c)

Figure 6. Sand A. Effect of the depth $z_{i}$ of the weak layer on the failure mechanisms observed in tests (a) B22, (b) B21 and (c) B49. Weak layer made of dry Luzenac 2 talc powder; shown by double bold lines

clearly influences $l_{\mathrm{m}}$ that becomes about twice as much as that for the homogeneous sand case for $z_{i} / B$ ranging from $2 \cdot 5$ to $2 \cdot 9$. The ratio $l_{\mathrm{m}} / B$ abruptly reduces when $z_{i} / B$ is about 3 . For $z_{i} / B>3$, the values of $l_{\mathrm{m}} / B$ are about the same as that observed for the homogeneous sand bed, irrespective of the material used for the weak layer. For values of $z_{i} / B$ of about $0 \cdot 5-0 \cdot 6, l_{\mathrm{m}} / B$ strongly depends on the shearing resistance of the weak layer; when the weak layer is made of humidified bentonite, $l_{\mathrm{m}}$ is very small, while when it is made of talc powder (both Baker and Luzenac 2), $l_{\mathrm{m}} / B$ is higher than the that of the homogeneous sand bed. The data in Table 3 show that the relation between $l_{\mathrm{m}} / B$ and the maximum depth $\left(z_{\mathrm{m}} / B\right)$ of the failure mechanism is approximately linear. The lateral extent of failure mechanism $l_{\mathrm{m}}$ is shorter than 


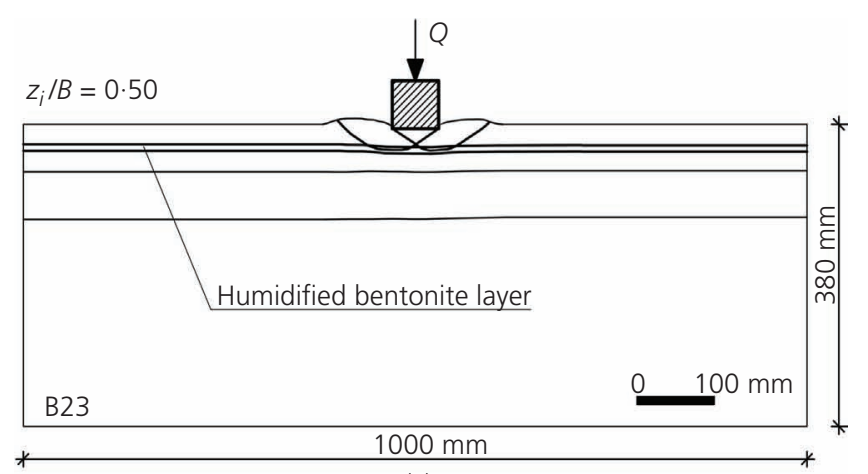

(a)

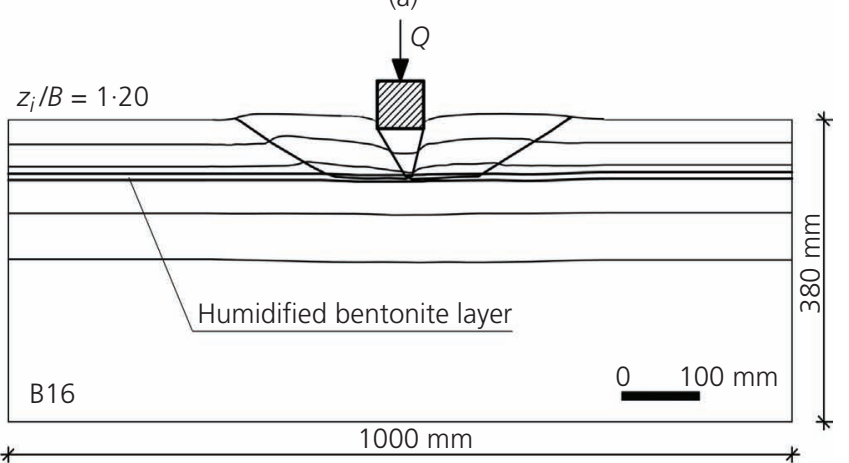

(b)

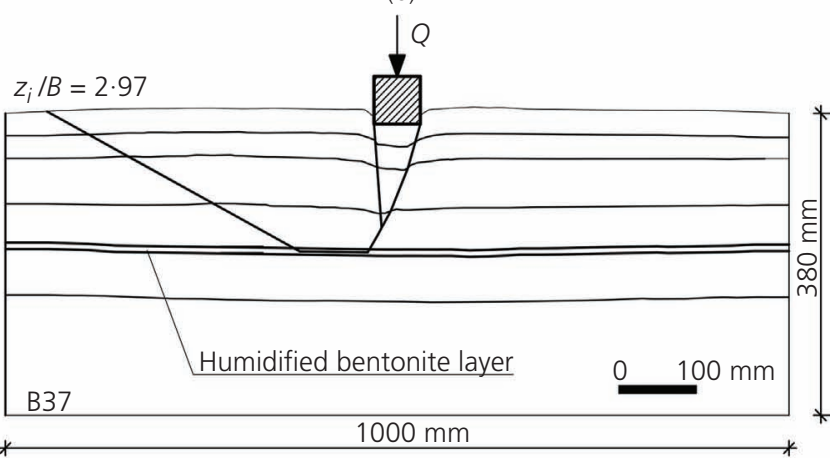

(c)

Figure 7. Sand A. Effect of the depth $z_{i}$ of the weak layer on the failure mechanisms observed in tests (a) B23, (b) B16 and (c) B37. Weak layer made of wet humidified bentonite; shown by double bold lines

that for the homogeneous sand bed $\left(l_{\mathrm{m}}=3 \cdot 25 B\right)$ if the depth of the weak layer $z_{i}$ is smaller than the footing width $B$, while it is larger when $z_{i}$ exceeds $B$.

\section{Bearing pressure-settlement curves}

Typical vertical pressure $(q)$-settlement $(\rho)$ curves are shown in Figures 13 and 14 for footing on sands A and B, respectively. They refer to a sand bed containing a thin weak layer made of humidified bentonite (test B16) or of dry Luzenac 2 talc powder (test B21). In both cases, the weak layer is located at a depth $z_{i}$ slightly larger than the footing width $B$. The experimental results of tests B06 and B60 relative to the homogeneous sand beds A and $\mathrm{B}$ are also plotted in the figures. The three curves are all characterised by a distinct peak corresponding to the ultimate bearing capacity, $q_{\mathrm{lim}}$. Beyond the peak, $q$ undergoes a conspicuous, but not abrupt, decrease. For tests on sand A, the settlement in the correspondence of the peak $\rho_{\text {lim }}$ varies from $8.3 \mathrm{~mm}$ (when the weak layer is missing; test B06) to $8.1 \mathrm{~mm}$ (test B21) and to $4.2 \mathrm{~mm}$ (test B16), while for tests on sand B, $\rho_{\text {lim }}$ ranges from $5 \cdot 1 \mathrm{~mm}$ (in the absence of the weak layer; test B60) to $6.2 \mathrm{~mm}$ (test B67) and to $5 \mathrm{~mm}$ (test B62). For tests on sand $\mathrm{A}$, the presence of the weak layer causes $q_{\mathrm{lim}}$ to reduce by $39 \%$ (from $375 \cdot 1$ to $230 \cdot 2 \mathrm{kPa}$ ) and by $61 \%$ (from $375 \cdot 1$ to $117 \cdot 6 \mathrm{kPa}$ ) for tests $\mathrm{B} 21$ and $\mathrm{B} 16$, respectively; for tests on sand $\mathrm{B}, q_{\mathrm{lim}}$ reduces by $41 \%$ (from 212 to $146 \mathrm{kPa}$ ) and by $46 \%$ (from 212 to $114 \mathrm{kPa}$ ) for tests $\mathrm{B} 67$ and $\mathrm{B} 62$, respectively. The regular post-peak behaviour is determined by the gradual reduction of the dilation angle of the sand and by the increase of the depth below the ground surface of the footing base and, of course, by the imposed constancy of the settlement rate.

Before approaching the peak, the 'stiffness' of the soil-footing system, as measured by $\Delta q / \Delta \rho$, in the presence of the weak layer is smaller than the one corresponding to the homogeneous case (Figures 13 and 14), for footings resting on both sands A and B.

\section{Influence of the weak layer on the ultimate bearing} capacity $q_{\lim }$

The ultimate bearing capacity, $q_{\text {lim }}$, has been normalised with respect to the ultimate bearing capacity relative to the sand bed without the weak layer, $q_{\lim , 0}$. The ultimate bearing pressure (at peak) of footings on a homogeneous sand bed, $q_{\mathrm{lim}, 0}$, is $375 \cdot 1 \mathrm{kPa}$ (for $B=60 \mathrm{~mm}$ ) and $212 \mathrm{kPa}$ (for $B=40 \mathrm{~mm}$ ) for footings on sands A and B, respectively. The ratio $\eta=q_{\lim } / q_{\lim , 0}$ is plotted against $z_{i} / B$ in Figure 15 .

Each set of experimental results referring to weak layers made of the same material can be interpolated by a curve showing an upwards concavity and a well-defined minimum value of $\eta$. The curve relative to the weak layers made of Baker talc powder, characterised by an angle of shear strength $\phi_{2 \mathrm{p}}^{\prime}=31^{\circ}$, shows a minimum at $z_{i} / B=2 \cdot 2$, at which the reduction in the ultimate bearing capacity, compared to the homogeneous sand case, amounts to $21 \cdot 5 \%$. The ultimate (or limit) bearing pressure (at peak) or ultimate bearing capacity, $q_{\lim }$, tends to $q_{\lim , 0}($ i.e. $\eta=1$ ) for $z_{i} / B$ higher than 4 . The curve relative to the weak layers made of Luzenac 2 talc powder $\left(\phi_{2 p}^{\prime}=18^{\circ}\right)$ attains its minimum at $z_{i} / B=1 \cdot 9$, with a remarkable decrease in $\eta$ of $40.5 \%$ (from $q_{\text {lim, }, 0}=375 \cdot 1 \mathrm{kPa}$ to $q_{\text {lim }}=223 \cdot 2 \mathrm{kPa}$ ). The ultimate (or limit) bearing pressure (at peak) or ultimate bearing capacity, $q_{\text {lim }}$, tends to $q_{\lim , 0}$ for $z_{i} / B$ larger than $4 \cdot 3$. The most dramatic reduction in $q_{\lim }$ occurs when the weak layer is made of humidified bentonite $\left(\phi_{2 \mathrm{p}}^{\prime}=11^{\circ}\right)$; in this case, the minimum value of the interpolating curve was not precisely identified, but occurs at a value of $z_{i} / B$ lower than $0 \cdot 5$. The interpolating curve is poorly defined within the interval of $z_{i} / B$ from 0 to $0 \cdot 5$, in which $q_{\text {lim }}$ rapidly drops down. The maximum reduction in $q_{\lim }$ amounts to $80 \% ; q_{\mathrm{lim}}$ tends to $q_{\mathrm{lim}, 0}$ for $z_{i} / B$ values larger than $4 \cdot 5$. 

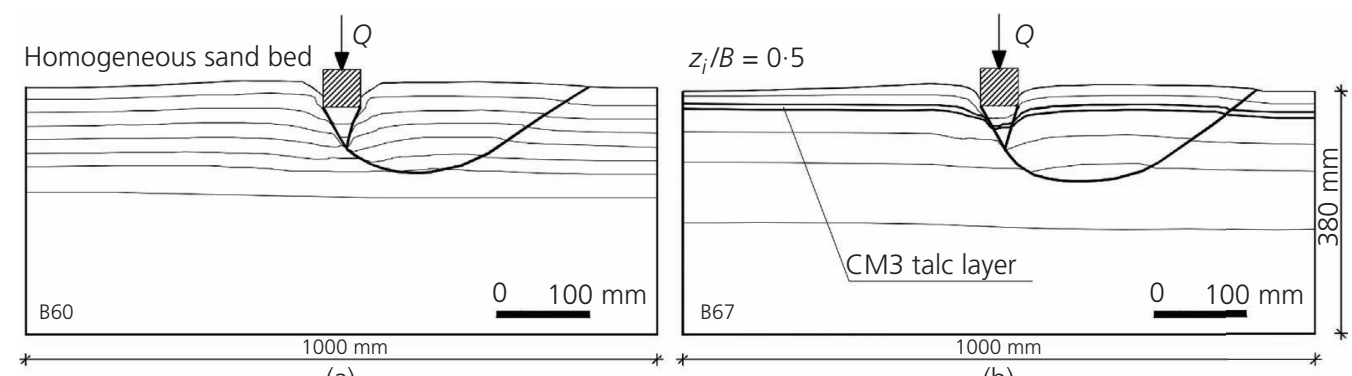

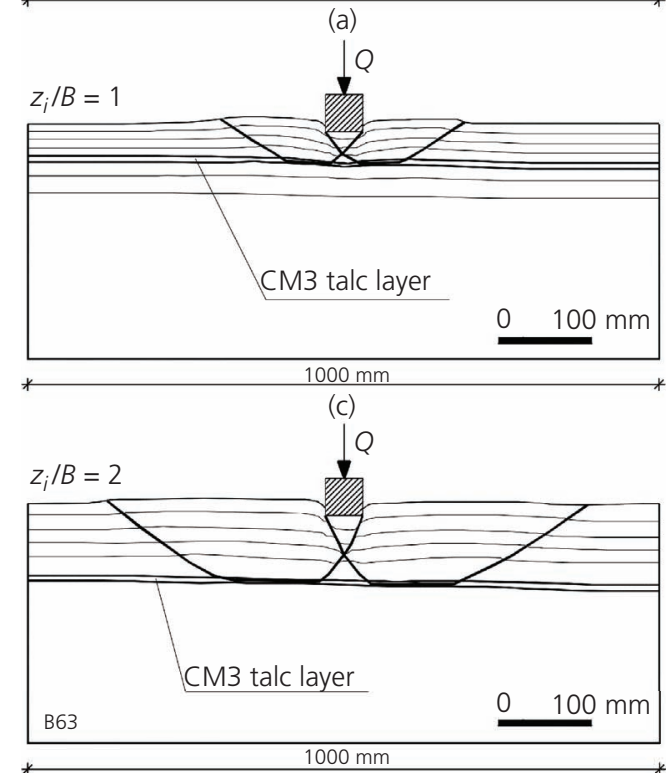

(e)

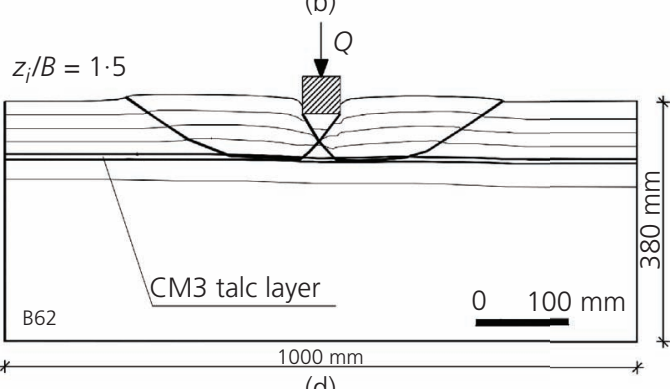

(d)

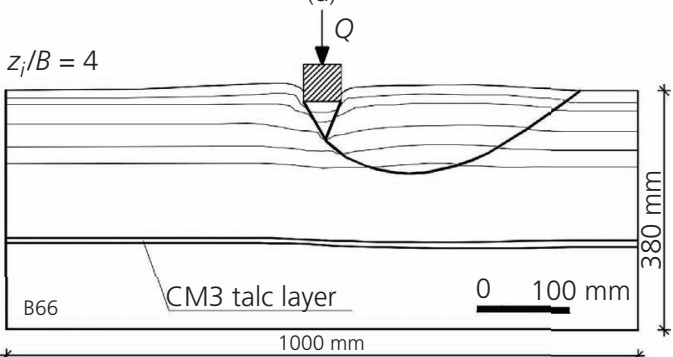

$(\mathrm{f})$

Figure 8. Footing on sand B. Failure mechanisms for (a) homogeneous sand bed, in the presence of (b-f) a thin weak layer. Thin lines are rows of monogranular blue-coloured sand particles adjacent to the box wall; they were initially horizontally aligned. Width of the footing $B=40 \mathrm{~mm}$. Weak layer shown as double bold lines

Results of tests carried out on sand B (weak layer made of CM3 talc powder with $\phi_{2 \mathrm{p}}^{\prime}=27^{\circ}$ ) show a minimum at $z_{i} / B=1 \cdot 7$, and the reduction in $q_{\mathrm{lim}}$, compared to $q_{\mathrm{lim}, 0}$, amounts to $45 \%$; $q_{\mathrm{lim}}$ tends to $q_{\mathrm{lim}, 0}$ for $z_{i} / B$ larger than 4 .

The above results clearly demonstrate the great importance of the presence of a weak layer on the ultimate bearing capacity, which can decrease by as much as $80 \%$. However, there is a threshold depth beyond which the influence of the weak layer becomes negligible, as expected. This depth is related to the shear strength of the material making up the weak layer. The effect of the weak layer on $q_{\text {lim }}$ depends essentially on $z_{i} / B$ and $\tan \phi_{1 \mathrm{p}}^{\prime} / \tan \phi_{2 \mathrm{p}}^{\prime}$.

The effects of the thin weak layer depend on the difference between the shear resistance and deformability parameters of the sand and those of the weak layer, as well as on the thickness and depth of the latter. These factors affect the failure mechanism, the ultimate bearing capacity and the settlements of the footing; they cannot be considered as separable variables. In any case, the reduction of the ultimate bearing capacity and the modification of the failure mechanism induced by the presence of the weak layer derive fundamentally from the limited capability of the weak layer to transfer shear stresses to the underlying sand; clearly, the lower the shear strength of the weak layer, the stronger its influence.

For footings on homogeneous sand, the ultimate bearing capacity factor $N_{\gamma}=2 q_{\mathrm{lim}} /(B \gamma)$ is equal to 781.5 and 670.9 for footings on sands $\mathrm{A}$ and $\mathrm{B}$, respectively. These values are in very good agreement with the values reported in the literature for dense sands (Cerato and Lutenegger, 2007 (Figure 16(b)); de Beer, 1963, 1965; Diaz-Segura, 2013; Meyerhof, 1951; Vesić, 1973 (Figure 16(a))). The sands used by Cerato and Lutenegger (2007) are as follows: the Winter sand, angular and well graded, $d_{50}=$ $0.7 \mathrm{~mm}, d_{10}=0.2 \mathrm{~mm}, C_{\mathrm{U}}=4.5, \gamma_{\mathrm{d}}=18.8 \mathrm{kN} / \mathrm{m}^{3}, D_{\mathrm{r}}=87 \%$ and $\phi_{\mathrm{cV}}^{\prime}=40^{\circ}$; the brown mortar sand, less angular and well-graded than Winter sand, $d_{50}=0.6 \mathrm{~mm}, d_{10}=0.3 \mathrm{~mm}, C_{\mathrm{U}}=2.1, \gamma_{\mathrm{d}}=$ $15 \cdot 9 \mathrm{kN} / \mathrm{m}^{3}, D_{\mathrm{r}}=70 \%$ and $\phi_{\mathrm{cv}}^{\prime}=38^{\circ}$.

\section{Back-analysis}

The numerical simulations were performed with reference to the reduced-scale physical model. The dilation angle of the sands, $\psi_{1 \mathrm{p}}^{\prime}$, 
The bearing capacity of footings on sand with a weak layer

Valore, Ziccarelli and Muscolino


Figure 9. Test B06: footing on homogeneous sand A. Evolution of the displacements field, obtained by PIV analysis, in function of the applied pressure $q$ and corresponding settlement $\rho$ of the footing. The ratios $q / q_{\text {lim }}$ and $\rho / \rho_{\text {lim }}$ are indicated. $q_{\lim }=375.1 \mathrm{kPa} ; \rho_{\text {lim }}=$ $8.29 \mathrm{~mm}$ : settlement at ultimate bearing pressure $q_{\text {lim; }} q$ : current applied vertical pressure. White dashed line: failure mechanism

was evaluated according to Bolton (1986) as $\psi_{1 \mathrm{p}}^{\prime}=1.25\left(\phi_{1 \mathrm{p}}^{\prime}\right.$ $\left.\phi_{1 \mathrm{cv}}^{\prime}\right), \phi_{1 \mathrm{cv}}^{\prime}\left(34^{\circ}\right.$ for sand $\mathrm{A}$ and $32^{\circ}$ for sand $\left.\mathrm{B}\right)$ being the angle of shearing resistance at constant volume (i.e. at critical porosity). In finite-element (FE) back-analyses, the angle of the shearing resistance of the weak layer was assumed to be known, constant and equal to the one determined by direct shear tests; the dilation angle was considered nil. The back-analysis aimed at the determination of the secant mean equivalent constant angle of shearing resistance of the sand.

The main aim of the analyses is to back-calculate by successive trials an operative equivalent mean secant value of both the angle


Figure 10. Test B21: footing on sand A containing a horizontal weak layer made of Luzenac 2 dry talc powder. Evolution of the displacements field, obtained by PIV analysis, in function of the applied pressure $q$ and of the corresponding settlement $\rho$ of the footing. The ratios $q / q_{\lim }$ and $\rho / \rho_{\lim }$ are indicated. $q_{\lim }=$ $230.2 \mathrm{kPa} ; \rho_{\text {lim }}=8.1 \mathrm{~mm}$ : settlement at ultimate bearing pressure $q_{\text {limi }} q$ : current applied vertical pressure. White dashed line: failure mechanism

of shearing resistance, $\phi_{1 \mathrm{p}}^{\prime}$, and the dilation angle, $\psi_{1 \mathrm{p}}^{\prime}$, of the sand in correspondence of the ultimate bearing capacity, $q_{\mathrm{lim}}$. The unit weight of the materials and the angle of shearing resistance of the weak layer were assumed to be known. The cohesion intercept is always considered negligible. Plane strain state and drained conditions are assumed. To avoid mesh-related dissymmetries, only half of the model was analysed. The reference scheme for FE analysis along with the boundary conditions is shown in Figure 17. The vertical load $Q$ corresponds to an average bearing pressure $q$ on the soil-footing interface. Actually, a uniform 
The bearing capacity of footings on sand

with a weak layer

Valore, Ziccarelli and Muscolino

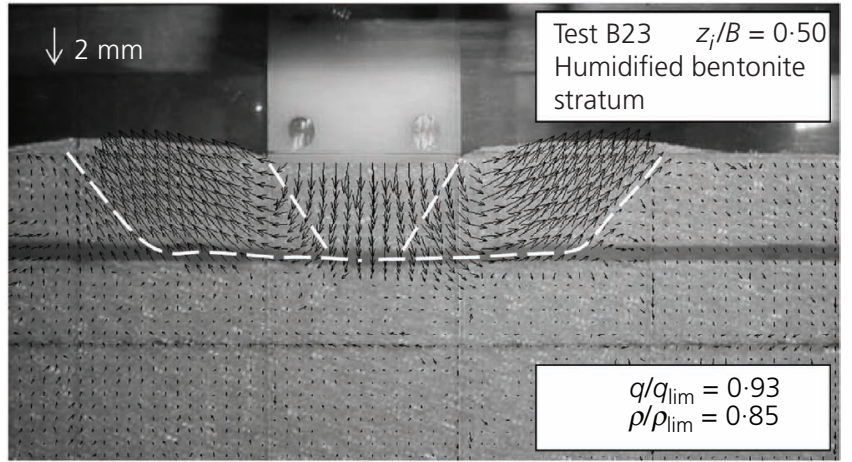

Figure 11. Test B23: footing on sand A containing a horizontal weak layer made of humidified bentonite. Evolution of the displacements field, obtained by PIV analysis, in function of the applied pressure $q$ and of the corresponding settlement $\rho$ of the footing. The ratios $q / q_{\lim }$ and $\rho / \rho_{\text {lim }}$ are indicated. $q_{\lim }=80.4 \mathrm{kPa}$; $\rho_{\text {lim }}=1.7 \mathrm{~mm}$ : settlement at ultimate bearing pressure $q_{\text {limi }} q$ : current applied vertical pressure. White dashed line: failure mechanism

vertical settlement of the footing base is imposed instead, so as to reproduce the real experimental procedure and accounting for the high stiffness of the footing and for the roughness of its base (Lee et al., 2013). The finite-element code Plaxis 2D (Plaxis, 2008) was used. For soils, the simple elastic-perfectly plastic Mohr-Coulomb constitutive model with non-associated flow rule has been adopted, similar to many researchers (Bolton and Lau, 1993; Hjiaj et al., 2005; Kumar and Khatri, 2011; Loukidis and

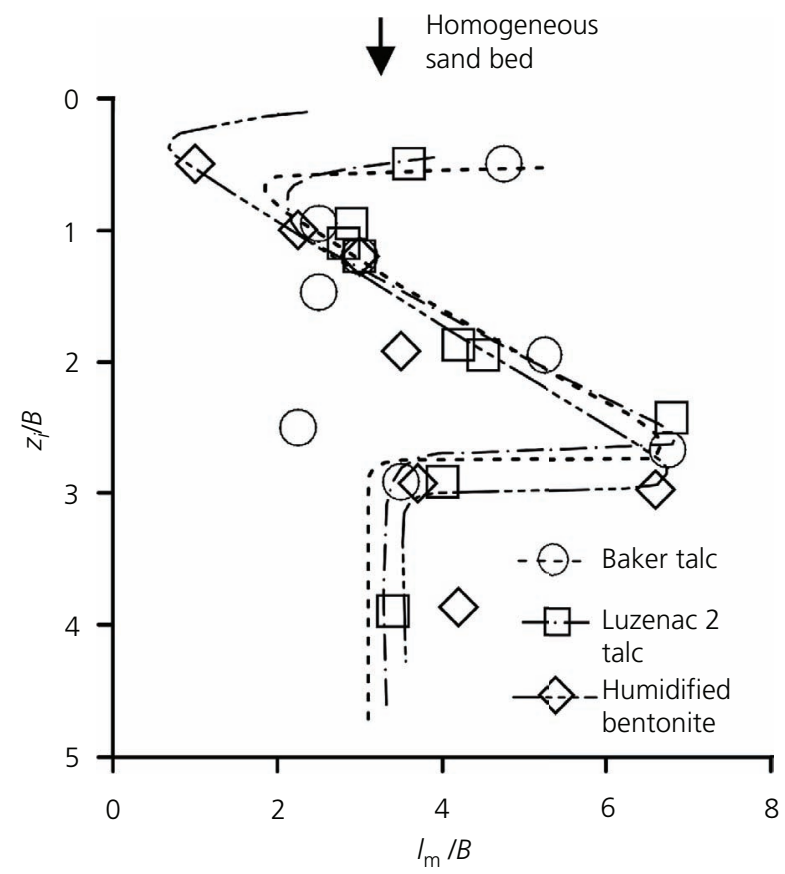

Figure 12. Relationship between the normalised lateral extent of the failure mechanism $\left(I_{\mathrm{m}} / B\right)$ and the depth of the weak layer $\left(z_{i} / B\right)$; footing resting on sand $A$. Footing width: $B=60 \mathrm{~mm}$



Figure 13. Footing on sand $A$. Typical bearing vertical pressure-settlement curves. $B=60 \mathrm{~mm}$. Test B16: weak layer made of humidified bentonite, $z_{i} / B=1 \cdot 20$. Test $B 21$ : weak layer made of Luzenac 2 talc powder, $z_{i} / B=1 \cdot 10$. Test B06: homogeneous silica sand, shown for comparison

Salgado, 2009; Potts, 2003; Yin et al., 2001). Geometric variations of the system were disregarded. The latter hypothesis and the assumption of perfect plasticity imply that pre-peak hardening, post-peak strain softening and spatial dependence of

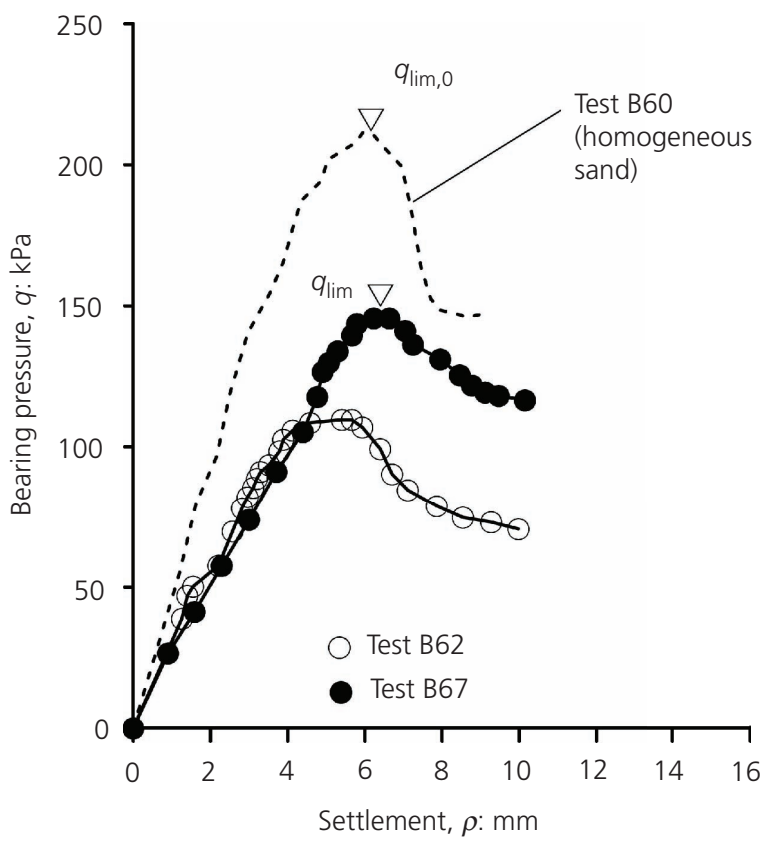

Figure 14. Footing on sand $B$. Typical vertical bearing pressure-settlement curves. $B=40 \mathrm{~mm}$. Weak layer made of $\mathrm{CM} 3$ talc powder. Test B62: $z_{j} / B=1 \cdot 5$. Test $B 67: z_{j} / B=0 \cdot 5$. Test $B 60$ : homogeneous silica sand, shown for comparison 
The bearing capacity of footings on sand

with a weak layer

Valore, Ziccarelli and Muscolino



(a)

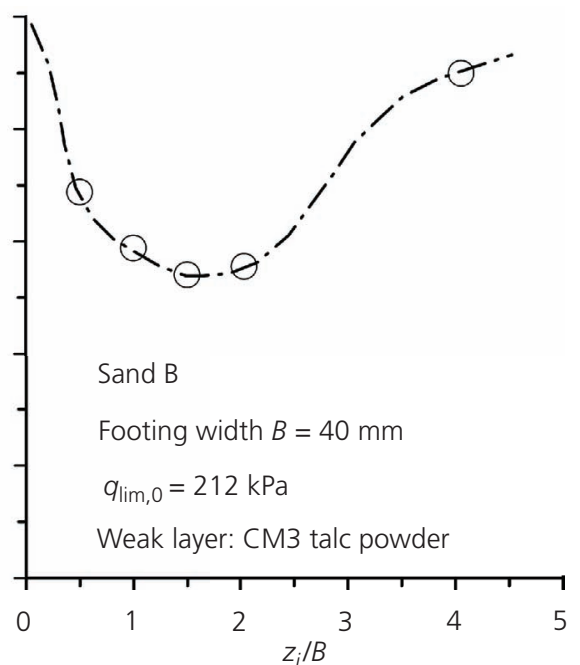

(b)

Figure 15. Normalised bearing capacity $q_{\lim } / q_{\lim , 0}$ against normalised depth of the weak layer $z_{j} / B$ for (a) footing on sand $A$ and (b) footing on sand B. $q_{\text {lim,o: }}$ : ultimate bearing capacity of footing on homogeneous sand

the angle of shear resistance, $\phi_{1 \mathrm{p}}^{\prime}$, on stress level have not been taken into account.

Possible small effects linked to the progressive failure phenomenon (Bishop, 1967) were not considered, according to the observations made by many researchers on the basis of $1 \mathrm{~g}$, large- and small-scale and centrifuge tests (Hettler and Gudheus, 1988; Lau and Bolton, 2011a; Muhs, 1965; Yamaguchi et al., 1976, 1977). Muhs (1965) detected progressive failure in largescale tests (square footing, base area of the footing $=1 \mathrm{~m}^{2}$ ) and observed that it depended on the deformation level before failure and on the settlements of the footing; he considered that it is significant only for large settlements. Yamaguchi et al. (1976) found a marked localisation of the shear strains, by using the $\mathrm{X}$-ray technique, but this observation refers only to the post-peak phase. Hettler and Gudheus (1988) found that the shear band influences the load-displacement curve mainly after the peak, and hence, an analysis of progressive failure is not necessary for the determination of the peak load. Lau and Bolton (2011a) recently observed that no strong evidence of progressive failure has been found in their tests.

The bearing pressure-settlement curves are back-calculated only up to the peak. Actually, the angle of shearing strength depends

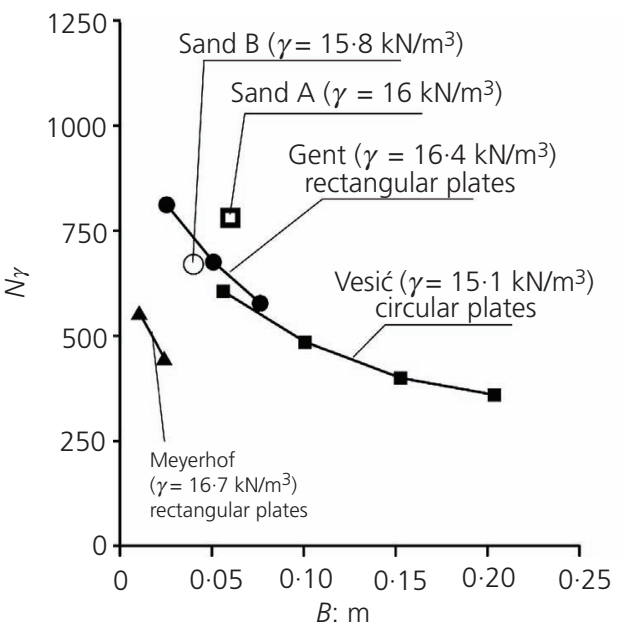

(a)

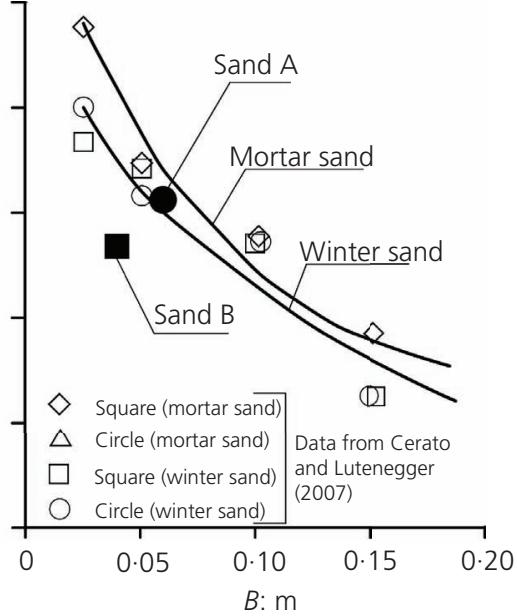

(b)

Figure 16. Ultimate bearing capacity factors, $N_{\gamma_{1}}$ plotted against $B$, compared (a) with results of de Beer (1963, 1965), Vesić (1973) and Meyerhof (1951) and (b) with results of Cerato and Lutenegger (2007) 
Geotechnical Research

Volume 4 Issue GR1
The bearing capacity of footings on sand

with a weak layer

Valore, Ziccarelli and Muscolino

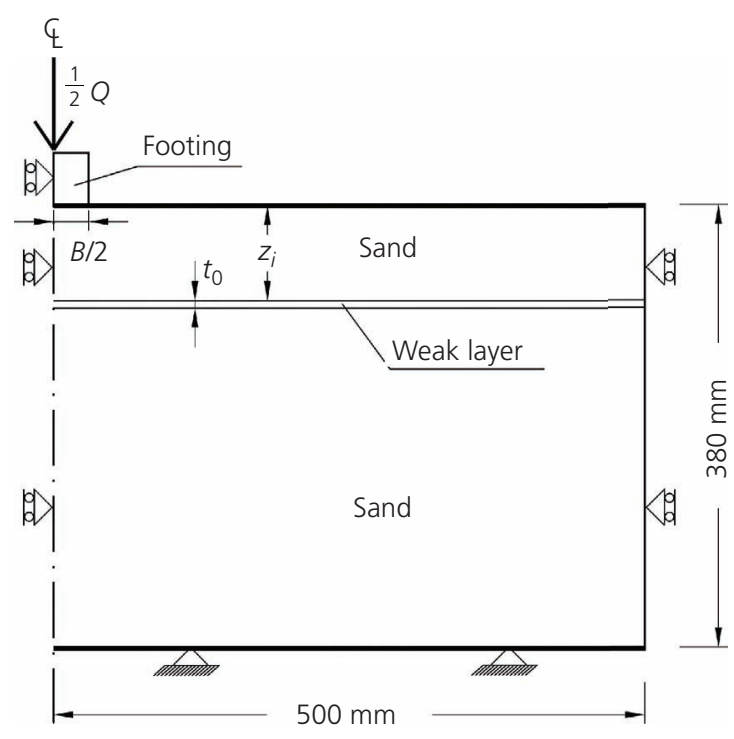

Figure 17. Reference scheme for FE analysis. Q: vertical load applied to the footing

on the effective stress level and, consequently, it varies within the relevant soil volume, from 'low' values in the soil beneath the footing (where the effective normal stresses are relatively 'high') to 'high' values within the passive zone where the stresses in tested physical models are extremely low (Lau and Bolton, 2011a, 2011b).

\section{Homogeneous sand bed}

The homogeneous sand bed-footing system was first backanalysed. Experimental and calculated results (tests B06 and B60 for footing on sands A and B, respectively) agree fairly well as far as the ultimate bearing pressure, $q_{\mathrm{lim}, 0}$, and the bearing pressure-settlement curve (up to $q_{\mathrm{lim}, 0}$ ) are concerned; see Figures 18 and 19. The following parameters of the sand were used: Young's modulus $E^{\prime}=$ $10^{4} \mathrm{kPa}$, Poisson's ratio $v^{\prime}=0 \cdot 15$, angle of shear strength $\phi_{1 \mathrm{p}}^{\prime}=$ $52.3^{\circ}$ angle of dilation $\psi_{1 \mathrm{p}}^{\prime}=22.9^{\circ}$ and $K_{0}=0.4$.



Figure 18. Footing on homogeneous sand A. Incremental shear strains at failure

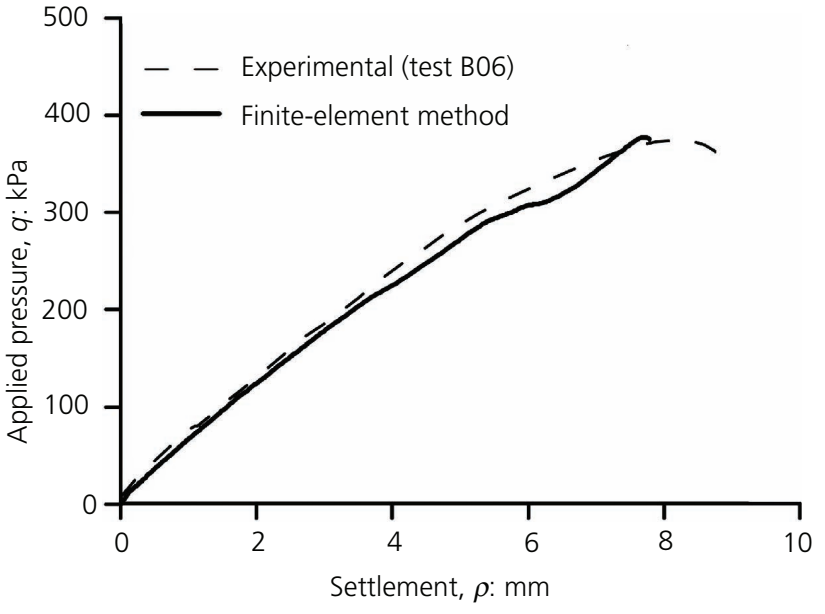

Figure 19. Footing on homogeneous sand A. Load-settlement curves from Test B06

The back-calculation satisfactorily captures the failure mechanism and the load-settlement curve. The back-calculated values of $\phi_{1 \mathrm{p}}^{\prime}$ and $\psi_{1 \mathrm{p}}^{\prime}$ are in good agreement with shear strength parameters obtained from triaxial and direct shear tests (sand A) and from direct shear tests for sand B, at low effective stress levels. The small instability of numerical results in the pre-peak range (see Figure 19) is due to the large difference between the peak shear strength angle, $\phi_{1 \mathrm{p}}^{\prime}$, and the peak dilation angle, $\psi_{1 \mathrm{p}}^{\prime}$, and to the non-associativity of the constitutive model adopted (Frydman and Burd, 1997; Potts and Zdravkovic, 1999, 2001; Yin et al., 2001).

\section{Sand bed with a weak layer}

The numerical analysis, despite the adopted simplifying assumptions, allows one to find out the failure mechanisms which match the experimentally observed ones very well as shown - for example, in Figure 20. This latter is to be compared with the results of test B22 (footing on sand A; weak layer made of Luzenac 2 talc powder; Figure 6). The values of Young's modulus, of Poisson's ratio and of the dry unit weight, $\gamma_{\mathrm{d} 2}$, of the



Figure 20. Incremental shear strains at failure for $z_{i} / B=0 \cdot 5$. Weak layer made of Luzenac 2 talc powder. Compare with test B22 (sand $A$; footing width $B=60 \mathrm{~mm}$ ) 
The bearing capacity of footings on sand with a weak layer

Valore, Ziccarelli and Muscolino weak layer have been assumed to be equal to that of the sand bed $\left(E^{\prime}=10^{4} \mathrm{kPa}, v^{\prime}=0 \cdot 15, \gamma_{\mathrm{d} 2}=16 \cdot 1 \mathrm{kN} / \mathrm{m}^{3}\right)$. Other parameters of the weak layer were as follows: Baker talc powder: $\phi_{2 \mathrm{p}}^{\prime}=31^{\circ}$, $K_{0}=0 \cdot 4$; Luzenac 2 talc powder: $\phi_{2 \mathrm{p}}^{\prime}=18^{\circ}, K_{0}: 1-\sin \phi_{2 \mathrm{p}}^{\prime}$; humidified bentonite: $\phi_{2 \mathrm{p}}^{\prime}=11^{\circ}, K_{0}: 1-\sin \phi_{2 \mathrm{p}}^{\prime}$; CM3 talc powder: $\phi_{2 \mathrm{p}}^{\prime}=27^{\circ}, K_{0}=0 \cdot 4$. The calculations were performed assuming for sand $\mathrm{A}$ the values of $\phi_{1 \mathrm{p}}^{\prime}=52.3^{\circ}$ and $\psi_{1 \mathrm{p}}^{\prime}=22.9^{\circ}$ retrieved from the analysis of test $\mathrm{B} 06$ on homogeneous sand $\mathrm{A}$ and $\phi_{1 \mathrm{p}}^{\prime}=50^{\circ}$ and $\psi_{1 \mathrm{p}}^{\prime}=22 \cdot 5^{\circ}$ obtained from the back-analysis of test B60 on homogeneous sand B. In the case of test B22, in which the weak layer is located at $z_{i}=0.5 \mathrm{~B}$, the failure mechanism crosses the weak layer, develops through a radial shear zone inside the sand underlying the weak layer and then runs upwards along a plane, inclined by $31 \cdot 3^{\circ}$, which crosses the weak layer again before emerging on the ground surface.

Results of computations performed assuming $\phi_{1 \mathrm{p}}^{\prime}=52 \cdot 3^{\circ}$ and $\psi_{1 \mathrm{p}}^{\prime}=22 \cdot 9^{\circ}$ for sand $\mathrm{A}$ and $\phi_{1 \mathrm{p}}^{\prime}=50^{\circ}$ and $\psi_{1 \mathrm{p}}^{\prime}=22 \cdot 5^{\circ}$ for sand

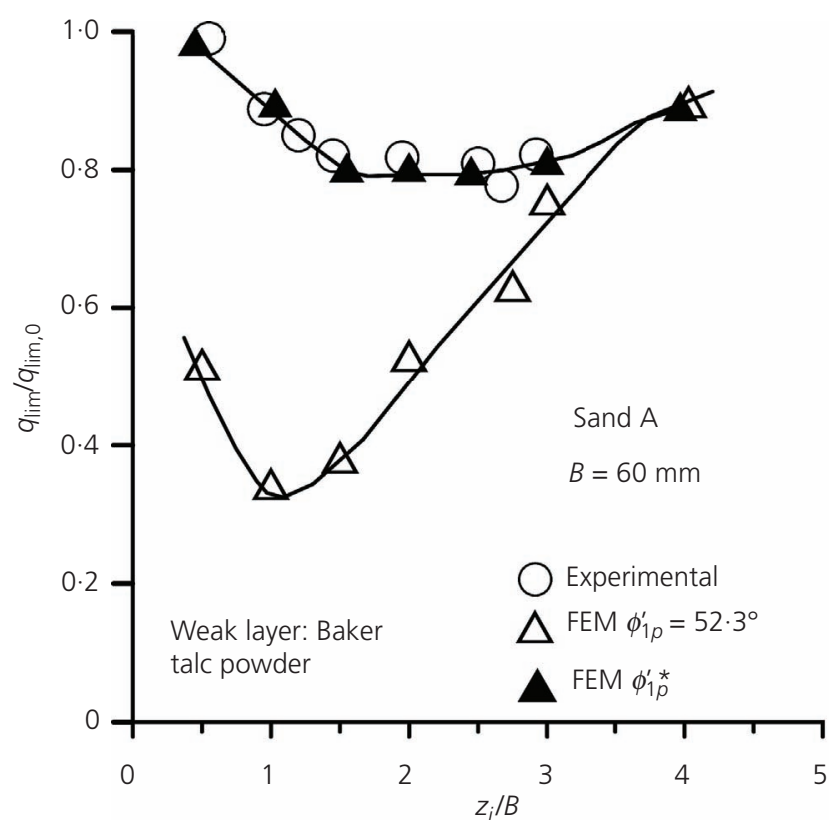

(a)

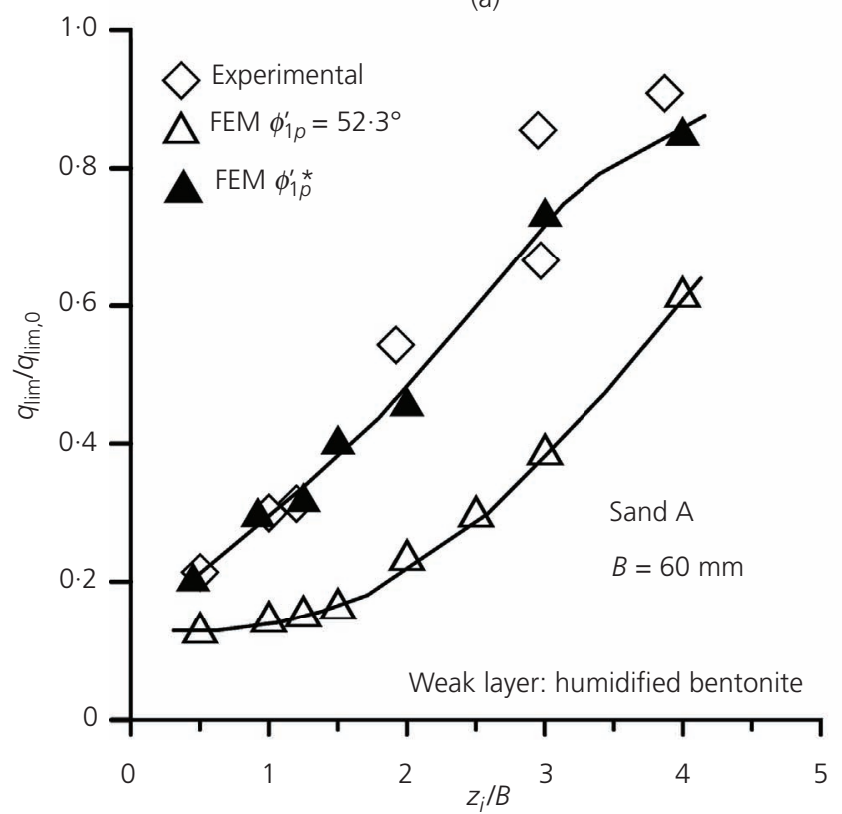

(c)



(b)

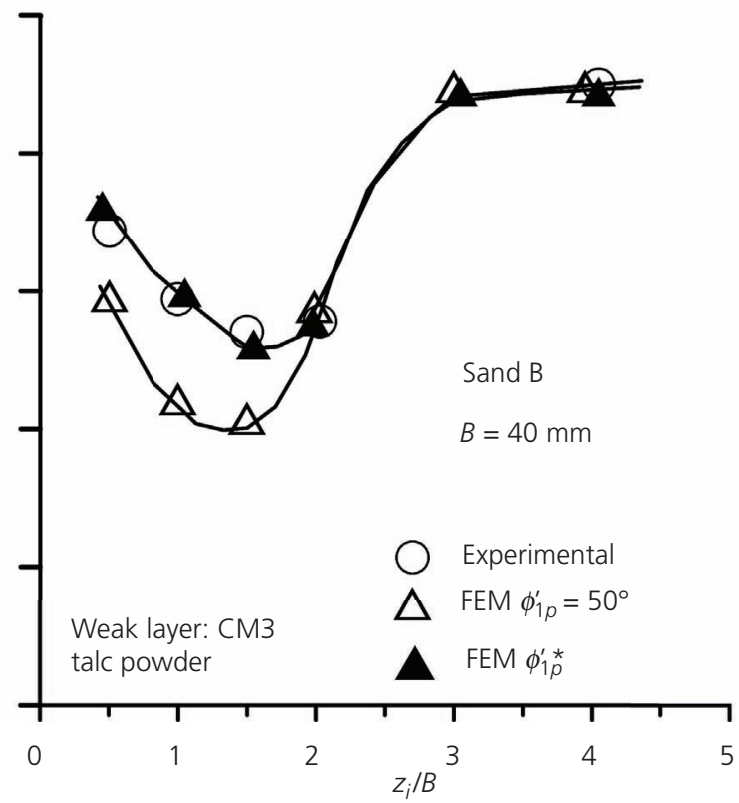

(d)

Figure 21. Results of back-calculations. $q_{\text {lim }} / q_{\lim , 0}$ in function of $z_{i} / B$. The value of $\phi_{1 \mathrm{p}}^{\prime *}$ pertinent to each test is reported in Tables 5 (sand $A$ ) and 6 (sand B). Weak layer made of (a) Baker talc powder, (b) Luzenac 2 powder, (c) humidified bentonite and (d) CM3 talc powder 
Table 5. Results of back-calculations for footing resting on sand bed A

\begin{tabular}{|c|c|c|c|c|c|c|c|}
\hline \multirow{3}{*}{$z_{i}: \mathrm{mm}$} & \multirow{3}{*}{$z_{i} / B$} & \multicolumn{6}{|c|}{ Material of weak layer } \\
\hline & & \multicolumn{2}{|c|}{ Baker talc powder } & \multicolumn{2}{|c|}{ Luzenac 2 talc powder } & \multicolumn{2}{|c|}{ Humidified bentonite } \\
\hline & & $\phi_{1 p}^{\prime \prime}{ }^{*}{ }^{\circ}$ & $\psi_{1 \mathrm{p}}^{\prime *}{ }^{*}$ & $\phi_{1 \mathrm{p}}^{\prime *}{ }^{*}$ & $\psi_{1 \mathrm{p}}^{\prime *}{ }^{*}$ & $\phi_{1 p}^{\prime *}: \circ$ & $\psi_{1 \mathrm{p}}^{\prime *}{ }^{*}{ }^{\circ}$ \\
\hline 30 & 0.50 & $55 \cdot 0$ & $26 \cdot 3$ & $56 \cdot 9$ & $28 \cdot 6$ & $56 \cdot 0$ & $27 \cdot 5$ \\
\hline 60 & 1.00 & $60 \cdot 8$ & 33.6 & $62 \cdot 6$ & $35 \cdot 8$ & $63 \cdot 0$ & $36 \cdot 2$ \\
\hline 75 & 1.25 & - & - & $60 \cdot 5$ & $33 \cdot 1$ & $61 \cdot 5$ & 34.4 \\
\hline 90 & 1.50 & $57 \cdot 5$ & $29 \cdot 4$ & $59 \cdot 5$ & 31.9 & $61 \cdot 1$ & 33.9 \\
\hline 120 & $2 \cdot 00$ & $57 \cdot 0$ & 28.8 & $56 \cdot 4$ & $28 \cdot 0$ & $61 \cdot 0$ & $33 \cdot 7$ \\
\hline 150 & $2 \cdot 50$ & $56 \cdot 4$ & $28 \cdot 1$ & $55 \cdot 5$ & $26 \cdot 9$ & - & - \\
\hline 180 & 3.00 & $56 \cdot 8$ & 23.5 & $53 \cdot 5$ & $24 \cdot 4$ & 58.7 & $30 \cdot 9$ \\
\hline 240 & 4.00 & $52 \cdot 3$ & $22 \cdot 9$ & - & - & $55 \cdot 3$ & $26 \cdot 6$ \\
\hline 255 & $4 \cdot 25$ & - & - & $52 \cdot 3$ & $22 \cdot 9$ & - & - \\
\hline
\end{tabular}

Mean secant equivalent values of the operative peak angle of shearing resistance $\phi_{1 \mathrm{p}}^{\prime *}$ and dilation angle $\psi_{1 \mathrm{p}}^{\prime *}$ of sand; $B=60 \mathrm{~mm}$

$\mathrm{B}$ are plotted as open triangles in Figure 21, along with the experimental results. It is evident from these figures that the backcalculated values of $q_{\lim }$ and, hence, of $q_{\lim } / q_{\lim , 0}$ are definitely lower than the experimental ones. The reason for this discrepancy is hidden in the hypothesis that only one value of $\phi_{1 \mathrm{p}}^{\prime}$ and $\psi_{1 \mathrm{p}}^{\prime}$ of the sand applies for all the experiments regardless of the depth of the weak layer and of its mechanical properties. The operatives $\phi_{1 \mathrm{p}}^{\prime *}$ and $\psi_{1 \mathrm{p}}^{\prime *}$ necessary to match the experimental values of $q_{\mathrm{lim}}$ and of $q_{\mathrm{lim}} / q_{\mathrm{lim}, 0}$ of each test have been found by trial and error and are summarised in Tables 5 (sand A) and 6 (sand B); the corresponding values of the calculated $q_{\lim }$ are plotted as solid triangles in Figure 21 and, of course, agree with experimental data. The results summarised in Tables 5 and 6 clearly show that the secant mean equivalent operative values of $\phi_{1 \mathrm{p}}^{\prime *}$ depend on both the depth and the mechanical properties of the weak layer. It can be observed that $\phi_{1 \mathrm{p}}^{\prime *}$ and $\psi_{1 \mathrm{p}^{*}}^{\prime *}\left(\psi_{1 \mathrm{p}}^{\prime *}\right.$ being linked to $\phi_{1 \mathrm{p}}^{\prime *}$ by Bolton's relation: $\left.\psi_{1 \mathrm{p}}^{\prime *}=1.25\left(\phi_{1 \mathrm{p}}^{\prime *}-\phi_{\mathrm{cv}}^{\prime}\right)\right)$ are higher when the length of the failure surface running along the weak layer is larger and the depth of the weak layer is smaller. These results clearly highlight the considerable relevance of the curvature of the failure envelope of the sand at very low effective normal stresses.

In other words, the numerical modelling, even though performed using a very simple constitutive model for soils, allows for the understanding of the fundamental aspects of the influence of a weak layer on the behaviour of shallow strip footings. It is

Table 6. Results of back-analysis for footing resting on sand bed $B$

\begin{tabular}{|c|c|c|c|}
\hline \multirow{2}{*}{$z_{i}: \mathrm{mm}$} & \multirow{2}{*}{$z_{i} / B$} & \multicolumn{2}{|c|}{ CM3 talc powder } \\
\hline & & $\phi_{1 p}^{\prime *}:^{*}$ & $\psi_{1 \mathrm{p}}^{\prime *}:^{*}$ \\
\hline 20 & 0.5 & $50 \cdot 1$ & $22 \cdot 6$ \\
\hline 40 & 1.0 & $56 \cdot 5$ & $30 \cdot 6$ \\
\hline 60 & 1.5 & 55.0 & 28.8 \\
\hline 80 & $2 \cdot 0$ & $50 \cdot 0$ & 22.5 \\
\hline 120 & 3.0 & $50 \cdot 0$ & 22.5 \\
\hline 160 & $4 \cdot 0$ & $50 \cdot 0$ & $22 \cdot 5$ \\
\hline
\end{tabular}

Mean secant equivalent values of the operative peak angle of shearing resistance $\phi_{1 \mathrm{p}}^{\prime *}$ and dilation angle $\psi_{1 \mathrm{p}}^{\prime *}$ of sand; $B=40 \mathrm{~mm}$ able to capture the shape of the failure mechanism and the reduction of the ultimate bearing capacity observed in $1 \boldsymbol{g}$ tests on reduced-scale models, provided that due allowance is made for the dependence of the equivalent mean shear strength parameters on the effective normal stress level and on the depth of the weak layer.

\section{Conclusions}

The influence of a horizontal thin weak soil layer inside a sand bed on the mechanical behaviour of a strip footing loaded to failure was investigated by means of single-gravity ( $1 \mathrm{~g})$ tests on small-scale physical models. From the test results, the following conclusions can be drawn.

The weak layer strongly influences both the failure mechanism and the ultimate bearing capacity, $q_{\mathrm{lim}}$, if its depth does not exceed a critical value of about $4 B$ ( $B$ being the footing width). The failure mechanism cuts through the weak layer when it is located at small depths, $z_{i}$, beneath the footing except when its shear strength is very low; when the weak layer is located at larger depths, $z_{i}$ (however smaller than $4 B$ ), it forces the failure mechanism to run partly along the horizontal weak layer before rising through the upper sand layer and emerging on the ground surface.

The ultimate bearing capacity, $q_{\mathrm{lim}}$, is always lower than $q_{\lim , 0}$ (pertaining to the homogeneous sand bed). At a given depth of the weak layer, the decrease in $q_{\text {lim }}$ is higher the lower the angle of shearing strength of the weak layer. The experiments show that the reduction in $q_{\mathrm{lim}}$ can reach $80 \%$ when the weak layer is made of humidified bentonite. Numerical simulations of the behaviour of the reduced-scale physical model tests by FE analysis (even though using the very simple constitutive Mohr-Coulomb model) satisfactorily captures the failure mechanism and the ultimate bearing capacity, provided that the strong dependency of the angle of the shearing resistance of the sand at the extremely low stress level existing in the physical model is properly taken into account. Moreover, back-calculations point out that the mean equivalent mobilised angle of shearing resistance of the sand significantly depends also on the properties and depth of the weak layer. 
Another evident implication of this study's findings is that the geotechnical engineer should never overlook or disregard minor geologic details during site investigations.

It is well known that results of single-gravity experiments on small-scale physical models are not straightforwardly transposable to real problems due primarily to scale effects (Bolton and Lau, 1989; Cerato and Lutenegger, 2007; de Beer, 1963, 1965).

In order to investigate the scale effects concerning the problem at hand, centrifuge-enhanced gravity experiments have been carried out; their results are reported in a companion paper (Ziccarelli et al., 2017).

\section{Acknowledgements}

The partial financial support granted by the Ministero dell'Istruzione dell'Università e della Ricerca (Progetti di Rilevante di Interesse Nazionale: gallerie in 'sezione mista', Project: 9908328717 009) is gratefully acknowledged. The authors wish to thank the laboratory technicians Dr Eng. A. Casella and Dr Geol. G. Sapienza of the Geotechnical Laboratory of the University of Palermo for their assistance during the testing activity.

\section{REFERENCES}

Abelev AV and Lade PV (2004) Characterization of failure in crossanisotropic soil. Journal of Engineering Mechanics 130(5): 599-606, http://dx.doi.org/10.1061/(ASCE)0733-9399(2004)130:5(599).

Alshibli KA and Hasan A (2008) Spatial variation of void ratio and shear band thickness in sand using X-ray computed tomography. Géotechnique 58(4): 249-257, http://dx.doi.org/10.1680/geot.2008.58.4.249.

Arens E (1975) Ebene grundbruchversuche mit lotrecht und schräg belasteten streifengründungen. FBG, Technische Hochschule Aachen, Aachen, Germany, Issue 3 (in German).

ASTM (2004a) D 4253-00: Standard test methods for maximum index density and unit weight of soils using a vibratory table. ASTM International, West Conshohocken, PA, USA.

ASTM (2004b) D 4254-00: Standard test methods for minimum index density and unit weight of soils and calculation of relative density. ASTM International, West Conshohocken, PA, USA.

Bishop AW (1967) Progressive failure - with special reference to the mechanism causing it. Proceedings of Geotechnical Conference on Shear Strength Properties of Natural Soils and Rocks, Oslo, Norway, vol. 2, pp. 142-150.

Bolton MD (1986) The strength and dilatancy of sands. Géotechnique 36(1): 65-78, http://dx.doi.org/10.1680/geot.1986.36.1.65.

Bolton MD and Lau CK (1989) Scale effects in the bearing capacity of granular soils. Proceedings of the 12th International Conference on Soil Mechanics and Foundation Engineering, Rio de Janeiro, Brazil, vol. 2, pp. 895-898.

Bolton MD and Lau CK (1993) Vertical bearing capacity factors for circular and strip footings on Mohr-Coulomb soil. Canadian Geotechnical Journal 30(6): 1024-1033.

Celauro C, Ziccarelli M, Parla G and Valore C (2014) An automated procedure for computing the packing properties of dense and locked sands by image analysis of thin sections. Granular Matter 16(6): 867-880, http://dx.doi.org/10.1007/s10035-014-0532-2.

Cerato AB and Lutenegger AJ (2007) Scale effect of shallow foundation bearing capacity on granular material. Journal of Geotechnical and Geoenvironmental Engineering 133(10): 1192-1202, http://dx.doi.org/ 10.1061/(ASCE)1090-0241(2007)133:10(1192).
Chakraborty T and Salgado R (2010) Dilatancy and shear strength of sand at low confining pressures. Journal of Geotechnical and Geoenvironmental Engineering 136(3): 527-532, http://dx.doi.org/10. 1061/(ASCE)GT.1943-5606.0000237.

de Beer EE (1963) The scale effect in the transposition of the results of deep sounding tests on the ultimate bearing capacity of piles and caisson foundations. Géotechnique 11(1): 39-75, http://dx.doi.org/10. 1680/geot.1963.13.1.39.

de Beer EE (1965) The scale effect on the phenomena of progressive rupture in cohesionless soils. Proceedings of the 6th International Conference on Soil Mechanics and Foundation Engineering, Montreal, QC, Canada, vol. 2, pp. 13-17.

Diaz-Segura EG (2013) Vertical assessment of the range of variation of $N_{\gamma}$ from 60 estimation methods for footings on sand. Canadian Geotechnical Journal 50(7): 793-800, http://dx.doi.org/10.1139/cgj-2012-0426.

Domitrovic D and Kovacevic Zelic B (2013) The relationship between swelling and shear strength properties of bentonites. Proceedings of the 18th International Conference on Soil Mechanics and Geotechnical Engineering, Paris, France, vol. 1, pp. 219-222.

Finno RJ, Harris WW, Mooney MA and Viggiani G (1997) Shear bands in plane strain compression of loose sand. Géotechnique 47(1): 149-165, http://dx.doi.org/10.1680/geot.1997.47.1.149.

Frydman S and Burd HJ (1997) Numerical studies of the bearing capacity factor $N_{\gamma}$. Journal of Geotechnical Engineering 123(1): 20-29, http:// dx.doi.org/10.1061/(ASCE)1090-0241(1997)123:1(20).

Goto S, Park CS, Tatsuoka F and Molekamp F (1993) Quality of the lubrication layer used in element tests on granular materials. Soils and Foundations 33(2): 47-59.

Green GE and Bishop AW (1969) A note on the drained strength of sand under generalized strain conditions. Géotechnique 19(1): 144-149, http://dx.doi.org/10.1680/geot.1964.14.2.143.

Hansen B and Christensen NH (1969) Discussion on: 'Theoretical bearing capacity of very shallow footings' by Larkins A.L. Journal of Soil Mechanics and Foundations Division 95(SM6): 1568-1573.

Hattab M, Hammad T and Fleureau JM (2015) Internal friction angle variation in a kaolin/montmorillonite clay mix and microstructural identification. Géotechnique 65(1): 1-11, http://dx.doi.org/10.1680/ geot.13.P.081.

Hettler A and Gudheus G (1988) Influence of the foundation width on the bearing capacity factor. Soils and Foundations 28(4): 81-92, http:// doi.org/10.3208/sandf1972.28.4 81.

Hjiaj M, Lyamin AV and Sloan SW (2005) Numerical limit analysis solutions for the bearing capacity factor $\mathrm{N}_{\gamma}$. International Journal of Solids and Structure 42: 1681-1704, http://dx.doi.org/10.1016/j. ijsolstr.2004.08.002.

Hoque E and Tatsuoka F (1998) Anisotropy in elastic deformation of granular materials. Soils and Foundations 38(1): 163-179, http://dx. doi.org/10.3208/sandf.38.163.

Kumar J and Khatri VN (2008) Effect of footing width on $N_{\gamma}$ Canadian Geotechnical Journal 45(12): 1673-1684, http://dx.doi.org/10.1139/ T08-113.

Kumar J and Khatri VN (2011) Bearing capacity factors of circular foundations for a general $c-\phi$ soil using lower bound finite elements limit analysis. International Journal for Numerical and Analytical Method in Geomechanics 35(3): 393-405, http://dx.doi.org/10.1002/nag.900.

Kumar J and Kouzer KM (2007) Effect of footing roughness on bearing capacity factor $N_{\gamma}$. Journal of Geotechnical and Geoenvironmental Engineering 133(5): 502-511, http://dx.doi.org/10.1061/(ASCE)10900241(2007)133:5(502).

Lade PV and Duncan JM (1973) Cubical triaxial tests on cohesionless soil. Journal of Soil Mechanics and Foundation Division 99(SM10): 793-812.

Lancelot L, Shahrour I and AI Mahmoud M (2006) Failure and dilatancy properties of sand at relatively low stresses. Journal of Engineering Mechanics 132(12): 1396-1399, http://dx.doi.org/10.1061/(ASCE) 0733-9399(2006)132:12(1396). 
Lau CK and Bolton MD (2011a) The bearing capacity of footings on granular soils: II: experimental evidence. Géotechnique 61(8) 639-650, http://dx.doi.org/10.1680/geot.7.00206.

Lau CK and Bolton MD (2011b) The bearing capacity of footings on granular soils: I: numerical analysis. Géotechnique 61(8): 627-638, http://dx.doi.org/10.1680/geot.7.00207.

Lee KK, Cassidy MJ and Randolph MF (2013) Bearing capacity on sand overlying clay soils: experimental and finite element investigation of potential punch-through failure. Géotechnique 63(15): 1271-1284, http://dx.doi.org/10.1680/geot.12.P.175.

Leonards GA (1982) Investigation of failures. Journal of Geotechnical Engineering Division ASCE 108(GT2): 222-283.

Liu J and Iskander MG (2010) Modelling capacity of transparent soil. Canadian Geotechnical Journal 47(4): 451-460, http://dx.doi.org/10. 1139/T09-116

Loukidis D and Salgado R (2009) Bearing capacity of strip and circular footings in sand using finite elements. Computers and Geotechnics 36(5): 871-879, http://dx.doi.org/10.1016/j.compgeo.2009.01.012.

Loukidis D and Salgado R (2011) Effect of relative density and stress level on the bearing capacity of footings on sand. Géotechnique 61(2): 107-119, http://dx.doi.org/10.1680/geot.8.P.150.3771.

McMahon BT and Bolton MD (2011) Experimentally observed settlements beneath shallow foundations on sand. In Proceedings of 15th ECSMGE, Athens, Greece (Anagnostopoulos A, Pachakis M and Tsatsanifos C (eds)). IOS Press, Amsterdam, the Netherlands, vol. 1, pp. 749-754

Mesri G and Olson RE (1970) Shear strength of montmorillonite. Géotechnique 20(3): 261-270, http://dx.doi.org/10.1680/geot.1970.20. 3.261 .

Mesri A and Olson RE (1971) Discussion on: 'Shear strength of montmorillonite' by Sridharan A and Narasimha Rao S. Géotechnique 21(2): 180-181, http://dx.doi.org/10.1680/geot.1971.21.2.180.

Meyerhof GG (1951) The ultimate bearing capacity of foundations. Géotechnique 2(4): 301-332, http://dx.doi.org/10.1680/geot.1951.2.4. 301.

Mühlhaus HB and Vardoulakis I (1987) The thickness of shear bands in granular materials. Géotechnique 37(3): 271-283, http://dx.doi.org/10. 1680/geot.1987.37.3.271

Muhs H (1965) Discussion on: 'The scale effect on the phenomenon of progressive rupture in cohesionless soils by de Beer EE, Proceedings of the 6th International Conference on Soil Mechanics and Foundation Engineering, Montreal, vol. 2, pp. 13-17'. Proceedings of the 6th International Conference on Soil Mechanics and Foundation Engineering, Montreal, QC, Canada, vol. 3, pp. 419-421.

Muscolino SR (2001) L'influenza delle interfacce e dei dettagli costitutivi minori sulla stabilità delle fondazioni e delle gallerie. $\mathrm{PhD}$ thesis, Università di Catania, Catania, Italy (in Italian).

Negussey D and Vaid YP (1990) Stress dilatancy of sand at small stress ratio states. Soils and Foundations 30(1): 155-166, http://dx.doi.org/ 10.3208/sandf1972.30.155.

Oda M (1981) Anisotropic strength of cohesionless sands. Journal of Geotechnical Engineering Division ASCE 107(GT9): 1219-1231.

Plaxis (2008) Plaxis 2D, Version 8.6. Plaxis, Delft, the Netherlands. See http://www.plaxis.nl/ (accessed 01/02/2017).

Ponce VM and Bell JM (1971) Shear strength of sand at extremely low pressures. Journal of Soil Mechanics and Foundations Division ASCE 97(SM4): 625-638.

Potts DM (2003) Numerical analysis: a virtual dream or practical reality? Géotechnique 53(6): 535-573, http://dx.doi.org/10.1680/geot.2003.53. 6.535 .

Potts DM and Zdravkovic L (1999) Finite Element Analysis in Geotechnical Engineering: Theory. Thomas Telford, London, UK.

Potts DM and Zdravkovic L (2001) Finite Element Analysis in Geotechnical Engineering: Application. Thomas Telford, London, UK.

Prandtl L (1920) Über die härte plastischer körper: Nachrichten Von der Königlichen Gesellschaft der Wissenschaften zu Göttingen. In
Mathematisch-Physikalische Klasse. Weidmannsche Buchhandlung, Berlin, Germany, pp. 74-85 (in German).

Roscoe KH (1970) The influence of strains in soil mechanics. Géotechnique 20(2): 129-170, http://dx.doi.org/10.1680/geot.1970.20.2.129.

Rowe PW (1962) The stress-dilatancy relation for static equilibrium of an assembly of particle in contact. Proceedings of the Royal Society of London: A 269(1339): 500-527.

Rowe PW (1969) The relation between the shear strength of sands in triaxial compression, plane strain and direct shear. Géotechnique 19(1): 75-86, http://dx.doi.org/10.1680/geot.1969.19.1.75.

Rowe PW (1972) The relevance of soil fabric to site investigation practice. Géotechnique 22(2): 195-300, http://dx.doi.org/10.1680/geot. 1972.22.2.195

Rowe PW (1991) A reassessment of the causes of the Carsington embankment failure. Géotechnique 41(3): 395-421, http://dx.doi.org/ 10.1680/geot.1991.41.3.395.

Sayão ASF and Vaid YP (1996) Influence of intermediate principal stress on the deformations response of sand. Canadian Geotechnical Journal 26(1): 170-171, http://dx.doi.org/10.1139/t96-108-328.

Scott RF (1987) Failure. Géotechnique 37(4): 423-466, http://dx.doi.org/ 10.1680/geot.1987.37.4.423.

Skempton AW and Vaughan PR (1993) The failure of Carsington dam. Géotechnique 43(1): 151-173, http://dx.doi.org/10.1680/geot.1993.43. 1.151 .

Sture S, Costes NC, Batiste SN et al. (1998) Mechanics of granular materials at very low effective stresses. Journal of Aerospace Engineering ASCE 11(3): 67-72, http://dx.doi.org/10.1061/(ASCE) 0893-1321(1998)11:3(67).

Tatsuoka F (2001) Impacts on geotechnical engineering of several recent findings from laboratory stress-strain tests on geomaterials. In The 2000 Burmister Lecture at Columbia University, Geotechnics for Roads, Rail Tracks and Earth Structures (Correia A and Brandle H (eds)). Balkema, Rotterdam, the Netherlands, pp. 69-140.

Tatsuoka F and Haibara O (1985) Shear resistance between sand and smooth or lubricated surfaces. Soils and Foundations 25(1): 89-98, http://dx.doi.org/10.3208/sandf1972.25.89.

Tatsuoka F, Molenkamp F, Torii T and Hino T (1984) Behavior of lubrication layers of platens in element tests. Soils and Foundations 24(1): 113-128, http://dx.doi.org/10.3208/sandf1972.24.113.

Tatsuoka F, Okahara M, Tanaka T et al. (1991) Progressive failure and particle size effect in bearing capacity of a footing on sand. In Proceedings of ASCE Geotechnical Engineering Congress - 1991 (McLean FG, Campbell DA and Harris DW (eds)). American Society of Civil Engineers, Reston, VA, USA, Geotechnical Special Publication 27, pp. 788-802.

Taylor RN (1995) Centrifuges in modelling: principles and scale effects. In Geotechnical Centrifuge Tecnology (Taylor RN (ed.)). Blackie Academic and Professional, London, UK, pp. 19-33.

Terzaghi K (1929) Effects of minor geologic details on the safety of dams. In Geology and Engineering for Dams and Reservoirs. American Institute of Mining and Metallurgical Engineers, Technical Publication 215, pp. 31-44. Reprinted in Terzaghi K (1960) From Theory to Practice in Soil Mechanics: Selection from the writings of Karl Terzaghi. Wiley, Hoboken, NJ, USA, pp. 119-132.

Toyosawa Y, Itoh K, Kikkawa N, Yang JJ and Liu F (2013) Influence of model footing diameter embedded depth on particle size effect in centrifugal bearing capacity test. Soils and Foundations 53(2): 349-356.

Valore C and Ziccarelli M (2009) The evolution of grain-size distribution of sands under 1-D compression. In Proceedings of the 17th International Conference on Soil Mechanics and Geotechnical Engineering: 5-9 October 2009, Alexandria, Egypt (Hamza M, Shahien M and El-Mossallamy Y (eds)). IOS Press, Amsterdam, the Netherlands, vol. 1, pp. 84-88. Vesić AS (1973) Analysis of ultimate loads of shallow foundations. Journal of the Geotechnical Engineering Division ASCE 99(SMI): 45-73. 
Geotechnical Research

Volume 4 Issue GR1
The bearing capacity of footings on sand

with a weak layer

Valore, Ziccarelli and Muscolino
White DJ, Take WA and Bolton MD (2003) Soil deformation measurement using particle image velocimetry (PIV) and photogrammetry.

Géotechnique 53(7): 619-631, http://dx.doi.org/10.1680/geot.2003.53. 7.619.

Yamaguchi H, Kimura T and Fuji-i N (1976) On the influence of progressive failure on the bearing capacity of shallow foundations in dense sand. Soils and Foundations 16(4): 11-22, http://doi.org/10. 3208/sandf1972.16.4 11.

Yamaguchi H, Kimura T and Fuji-i N (1977) On the scale effect of footings in dense sand. Proceedings of the 9th International Conference on Soil
Mechanics and Foundation Engineering, Tokyo, Japan, vol. 2, pp. 795-798

Yin JH, Wang YJ and Selvadurai APS (2001) Influence of nonassociativity on the bearing capacity of a strip footing. Journal of Geotechnical and Geoenvironmental Engineering ASCE 127(11): 985-989, http://dx.doi org/10.1061/(ASCE)1090-0241(2001)127:11(985).

Ziccarelli M, Valore C, Muscolino SR and Fioravante V (2017) Centrifuge tests on strip footings on sand with a weak layer. Geotechnical Research, in press.

\section{How can you contribute?}

To discuss this paper, please submit up to 500 words to the editor at journals@ice.org.uk. Your contribution will be forwarded to the author(s) for a reply and, if considered appropriate by the editorial board, it will be published as a discussion in a future issue of the journal. 